\title{
Differential requirements for myeloid leukemia IFN- $\gamma$ conditioning determine graft-versus-leukemia resistance and sensitivity
}

\author{
Catherine Matte-Martone, ${ }^{1}$ Jinling Liu, ${ }^{2}$ Meng Zhou, ${ }^{2}$ Maria Chikina, ${ }^{3}$ Douglas R. Green, ${ }^{4}$ John T. Harty, ${ }^{5,6}$ \\ and Warren D. Shlomchik ${ }^{2,5,6}$
}

1Department of Medicine, Yale University School of Medicine, New Haven, Connecticut, USA. ²Department of Medicine, University of Pittsburgh School of Medicine, University of Pittsburgh Cancer Institute,

Pittsburgh, Pennsylvania, USA. ${ }^{3}$ Department of Computational Systems Biology, University of Pittsburgh, Pittsburgh, Pennsylvania, USA. ${ }^{4}$ Department of Immunology, St. Jude Children's Research Hospital,

Memphis Tennessee, USA. ${ }^{5}$ Department of Microbiology and Pathology, University of lowa, lowa City, lowa, USA. ${ }^{6}$ Department of Immunobiology, Yale University School of Medicine, New Haven, Connecticut, USA.

\begin{abstract}
The graft-versus-leukemia (CVL) effect in allogeneic hematopoietic stem cell transplantation (alloSCT) is potent against chronic phase chronic myelogenous leukemia (CP-CML), but blast crisis CML (BC-CML) and acute myeloid leukemias (AML) are CVL resistant. To understand GVL resistance, we studied CVL against mouse models of $C P-C M L, B C-C M L$, and $A M L$ generated by the transduction of mouse BM with fusion cDNAs derived from human leukemias. Prior work has shown that CD4 ${ }^{+} \mathrm{T}$ cellmediated CVL against CP-CML and BC-CML required intact leukemia MHCII; however, stem cells from both leukemias were MHCII negative. Here, we show that CP-CML, BC-CML, and AML stem cells upregulate MHCII in alloSCT recipients. Using genedeficient leukemias, we determined that $B C-C M L$ and $A M L ~ M H C$ upregulation required IFN- $\gamma$ stimulation, whereas CP-CML MHC upregulation was independent of both the IFN- $\gamma$ receptor (IFN- $\gamma \mathrm{R}$ ) and the IFN- $\boldsymbol{\alpha} / \boldsymbol{\beta}$ receptor IFNAR1. Importantly, IFN- $\gamma$ R-deficient BC-CML and AML were completely resistant to CD4- and CD8-mediated CVL, whereas IFN- $\gamma \mathrm{R}$ / IFNAR1 double-deficient CP-CML was fully GVL sensitive. Mouse AML and BC-CML stem cells were $\mathrm{MHCl}^{+}$without IFN- $\gamma$ stimulation, suggesting that IFN- $\gamma$ sensitizes these leukemias to T cell killing by mechanisms other than MHC upregulation. Our studies identify the requirement of IFN- $\gamma$ stimulation as a mechanism for BC-CML and AML GVL resistance, whereas independence from IFN- $\gamma$ renders CP-CML more GVL sensitive, even with a lower-level alloimmune response.
\end{abstract}

\section{Introduction}

Allogeneic hematopoietic stem cell transplantation (alloSCT) is the most successful and widely applied form of adoptive $\mathrm{T}$ cell immunotherapy. Alloreactive $\alpha \beta$ T cells in allografts can recognize and kill recipient leukemia cells, thereby mediating the graft-versus-leukemia (GVL) effect (1). Unfortunately, alloreactive $\mathrm{T}$ cells also attack nonmalignant host tissues, causing graftversus-host disease (GVHD) (2-4). A longstanding and elusive objective has been to develop approaches that preserve GVL while minimizing GVHD. A second and arguably more important goal is to overcome GVL resistance, as relapse of malignant neoplasms is the greatest single cause of post-transplantation mortality (5). GVL resistance and sensitivity are not equal across different types of hematopoietic malignancies. For example, chronic phase chronic myelogenous leukemia (CP-CML) is exquisitely GVL sensitive, whereas blast crisis CML (BC-CML) is relatively GVL resistant, despite the two sharing a common biology, in that both are reliant on breakpoint cluster region/ Abelson murine leukemia viral oncogene homolog 1 (BCR/ABL) signaling (6-8). Acute myeloid leukemias (AML) and acute lymphoblastic leukemias are also relatively GVL resistant.

Conflict of interest: The authors have declared that no conflict of interest exists Submitted: November 30, 2015; Accepted: April 20, 2017. Reference information: J Clin Invest. 2017;127(7):2765-2776. https://doi.org/10.1172/JCl85736.
Because GVL resistance and sensitivity track with the identity of the underlying neoplasm, we reasoned that they are leukemia cell-intrinsic properties. To understand the mechanisms of GVL resistance, we used mouse models to evaluate GVL against CP-CML (mCP-CML) and BC-CML (mBC-CML) (9-11). mCP-CML is created via retroviral transfer of the $B C R-A B L$ fusion CDNA, the defining genetic abnormality of CP-CML, into mouse BM cells $(12,13)$, whereas $\mathrm{BBC}-\mathrm{CML}$ is created via retroviral transfer of both $B C R-A B L$ and nucleoporin 98-homeobox A9 (NUP98-HOXA9) fusion cDNAs $(14,15)$. The NUP98-HOXA9 fusion is a second-hit translocation in BC-CML that has also been identified in de novo AML (14-22), as have NUP98 fusions with other class I HOX genes. MCP-CML and $\mathrm{mBC}-\mathrm{CML}$ are therefore excellent phenocopies and genocopies of their human counterparts, have defined stem cell populations $(15,23)$, and, importantly, are GVL sensitive and GVL resistant, respectively (11). A powerful advantage of this approach is that, by transducing BM from gene-deficient mice, we can create gene-deficient leukemias as a means to explore mechanisms of GVL resistance (10, 11, 24-26). Using these systems, we found that GVL against $\mathrm{mCP}-\mathrm{CML}$ and GVL against $\mathrm{mBC}-$ CML share essential features: (a) both leukemias must express ICAM1; (b) T cell killing mechanisms are highly redundant; and (c) $\mathrm{CD}^{+}$and $\mathrm{CD} 4^{+} \mathrm{T}$ cell killing requires $\mathrm{T}$ cell receptorMHCI (TCR-MHCI) or TCR-MHCII interactions, respectively (11, 24, 25). Paradoxically, however, despite the fact that 


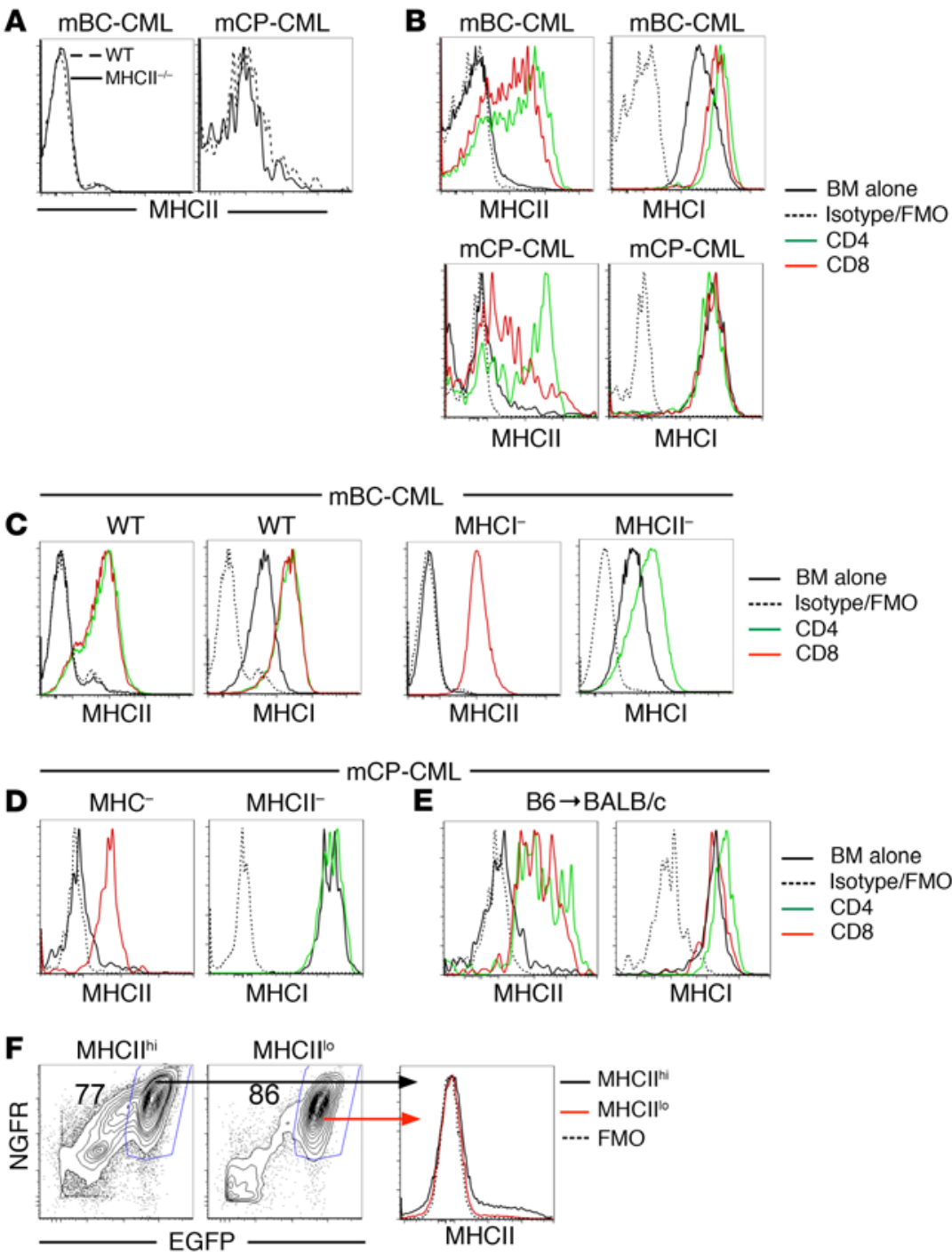

Figure 1. Expression of MHC molecules on $\mathrm{MCP}-\mathrm{CML}$ and $\mathrm{mBC}-\mathrm{CML}$ LSCs increases in the alloimmune environment, independently of cognate TCR-MHC interactions. $\mathrm{MHCll}$ expression on $\mathrm{WT}$ and $\mathrm{MHCII}^{-/-}$ mBC-CML (A, left) or mCP-CML (A, right) LSCs harvested from mice transplanted with leukemia cells but without CVH-inducing T cells. (B) Irradiated B6 mice were reconstituted with C3H.SW BM and CD4 or CD8 T cells and either $\mathrm{MBC}-\mathrm{CML}$ or $\mathrm{MCP}-\mathrm{CML}$. Mice were sacrificed between days 10 and 14, and LSCs were analyzed for $\mathrm{MHCl}$ and $\mathrm{MHCll}$ expression. Representative data from at least 3 independent experiments are shown. (C) Irradiated B6 mice were reconstituted with C3H.SW BM with $\mathrm{B} 6 \mathrm{B2m}^{-1-} \mathrm{mBC}-\mathrm{CML}\left(\mathrm{MHCl}^{-}\right)$and $\mathrm{C} 3 \mathrm{H} . \mathrm{SW}$ CD8 cells; B6 $\mathrm{MHCII}^{-1-} \mathrm{mBC}-\mathrm{CML}\left(\mathrm{MHCII}^{-}\right)$and $\mathrm{C} 3 \mathrm{H} .5 \mathrm{SW}$ CD4 cells; or WT B6 mBC-CML and C3H.SW CD4 or CD8 cells. On day 15 after $\mathrm{BMT}$, splenocytes were harvested, and $\mathrm{MHCl}$ and $\mathrm{MHCll}$ expression on $\mathrm{mBC}-\mathrm{CML}$ LSCs was assessed. Similar MHC upregulation was noted on LSCs harvested from BM (data not shown). Data are representative of 3 independent experiments. (D) Mice were transplanted as in C, except with $\mathrm{B}^{2 \mathrm{~m}^{-/-} \text {or } \mathrm{MHCII} /-/-} \mathrm{mCP}-\mathrm{CML}$ cells. MHC upregulation was also independent of TCR-MHC interactions. (E) Irradiated BALB/c mice were reconstituted with B6 BM and B6 MCP-CML with no T cells or with $\mathrm{B} 6 \mathrm{CD} 4$ or $\mathrm{CD} 8$ cells. MHCII and $\mathrm{MHCl}$ were upregulated on splenic mCP-CML LSCs on day 15 after BMT. Similar MHC upregulation was seen in BM LSCs (data not shown). (F) MHCI ${ }^{\text {hi }}$ and $\mathrm{MHCI}{ }^{10} \mathrm{mBC}-\mathrm{CML}$ LSCs from mice undergoing a $\mathrm{CVHD}$ response $(\mathrm{C} 3 \mathrm{H} . \mathrm{SW} \rightarrow \mathrm{B} 6$ model with $\mathrm{CVH}$ induced by CD4 cells) were sort purified and transferred into sublethally irradiated B6 mice. Both populations transferred disease (F, left panels). Progeny of sorted $\mathrm{MHCII}^{\text {hi }}$ and $\mathrm{MHCII}^{\mathrm{IO}} \mathrm{mBC}-\mathrm{CML}$ cells recovered 15 days after transfer were $\mathrm{MHCI}^{\text {Io }}$ (F, right panel). FMO, fluorescence minus one.
MHCII-deficient mCP-CML and $\mathrm{mBC}-\mathrm{CML}$ were completely resistant to CD4-mediated GVL, WT $\mathrm{mCP}-\mathrm{CML}$ and $\mathrm{mBC}$ CML leukemia stem cells (LSCs) expressed little to no surface MHCII, as MHCII staining was similar in WT and MHCIIdeficient LSCs (11). Here, we report that expression of MHCII and MHCI on $\mathrm{MBC}-\mathrm{CML}$ and MHCII on mouse AML (mAML; induced by transduction with the MLL-AF9 fusion cDNA) (27) and $\mathrm{MCP}-\mathrm{CML}$ LSCs is upregulated in the alloimmune environment. Upregulation of $\mathrm{MHC}$ on $\mathrm{MBC}-\mathrm{CML}$ and $\mathrm{MAML}$ required IFN- $\gamma$ receptor (IFN- $\gamma \mathrm{R})$ stimulation, whereas $\mathrm{MHC}$ upregulation on mCP-CML LSCs was entirely independent of IFN- $\gamma \mathrm{R}$ or IFN- $\alpha / \beta$ (IFNAR1) signaling. Importantly, IFN- $\gamma \mathrm{R}-$ deficient (Ifngr/-) $\mathrm{mBC}-\mathrm{CML}$ and $\mathrm{mAML}$ were highly resistant to both CD4- and CD8-mediated GVL, whereas Ifngr-/, Ifngr-/- Ifnarl-1-, and Stat1 $^{-/-}$Stat $^{-/-}$mCP-CML were fully GVL sensitive. Our data further suggest that IFN- $\gamma$ sensitizes myeloblastic leukemias to GVL by mechanisms beyond simply upregulating MHC. The differential requirements for IFN- $\gamma$ stimulation at least in part explain the exquisite GVL sensitivity of CP-CML and GVL resistance of myeloblastic leukemias and suggest a therapeutic strategy for overcoming the GVL resistance of myeloblastic leukemias.

\section{Results}

MHCII and MHCI are upregulated on leukemia cells in a GVH environment. Although $\mathrm{MHCII}^{-/} \mathrm{mCP}-\mathrm{CML}$ and $\mathrm{mBC}-\mathrm{CML}$ were completely resistant to CD4-mediated GVL, staining for surface MHCII on WT and $\mathrm{MHCII}^{-/-}$LSCs harvested from sublethally irradiated syngeneic recipients or alloBMT recipients that did not receive donor $\mathrm{T}$ cells was similar (ref. 11 and Figure 1A). To account for the MHCII requirement in GVL, we hypothesized that surface MHCII was upregulated in an alloimmune environment. To test this, we analyzed $\mathrm{mBC}-\mathrm{CML}$ and $\mathrm{mCP}-\mathrm{CML}$ cells from mice with or without an ongoing GVH response in the $\mathrm{C} 3 \mathrm{H} . \mathrm{SW} \rightarrow \mathrm{B} 6$ model. MHCII was upregulated on both $\mathrm{mBC}-\mathrm{CML}$ LSCs (lineage ${ }^{-}$ [lin-] or CD11b-) (ref. 15 and data not shown) and mCP-CML LSCs $\left(\right.$ lin $^{-}$sca- $1^{+}$c-kit ${ }^{+}$) (ref. 28 and Figure 1B) harvested from mice in which GVH was induced by either CD4 or CD8 cells. We found that MHCI was consistently upregulated on $\mathrm{mBC}-\mathrm{CML}$ LSCs but minimally and inconsistently so on mCP-CML LSCs (Figure 1B).

MHC upregulation does not require TCR-MHC interactions. Because CD4-mediated GVL absolutely requires both $\mathrm{MCP}-\mathrm{CML}$ and $\mathrm{mBC}-\mathrm{CML}$ to express MHCII $(10,11,24)$, we reasoned that MHCII upregulation would occur in the GVH environment inde- 

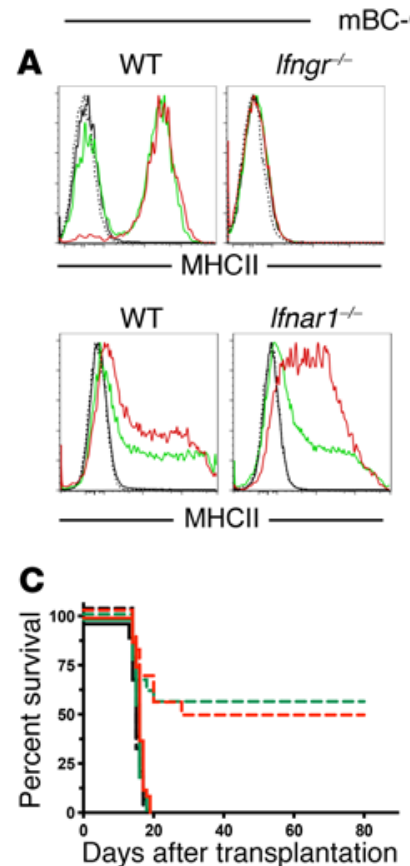

IFN-pR BC-CML/CD8 $(n=32)$

IFN-YR BC-CML CD4 $(n=30$

- IFN-yR BC-CML BM $(n=28)$

- WT BC-CML/CD8 $(n=15)$

WT BC-CML/CD4 $(n=18)$

- WT BC-CML/ BM $(n=14)$

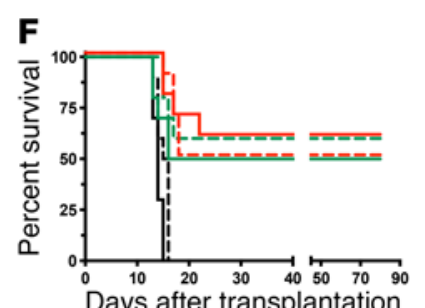

S after transplantation

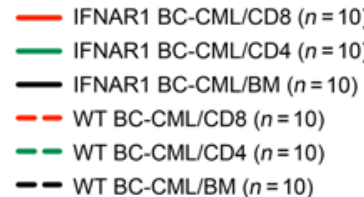

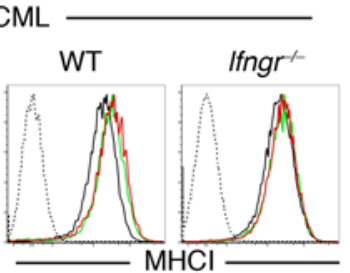
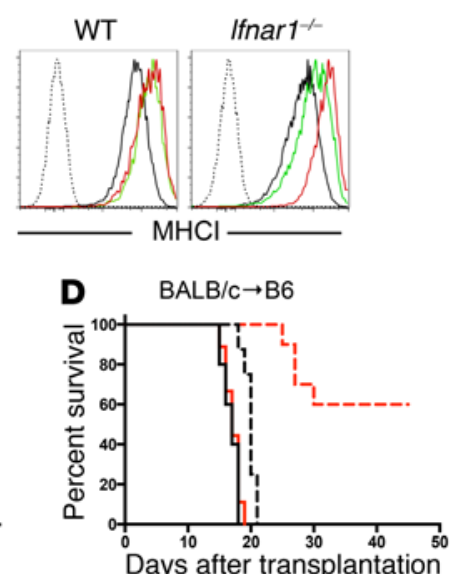

IFN-yR BC-CML/BM $(n=10)$

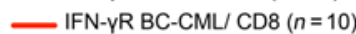

- WT BC-CML/BM $(n=9)$

- WT BC-CML/CD8 $(n=10)$
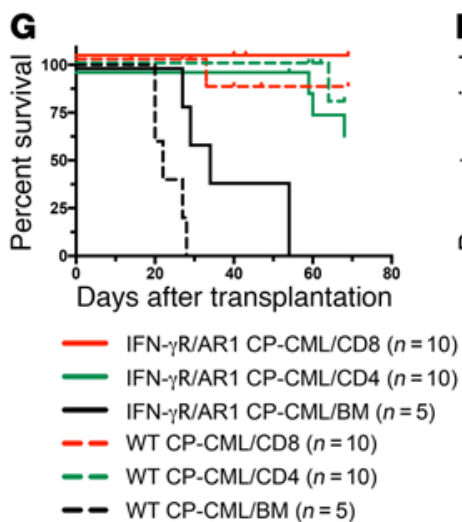
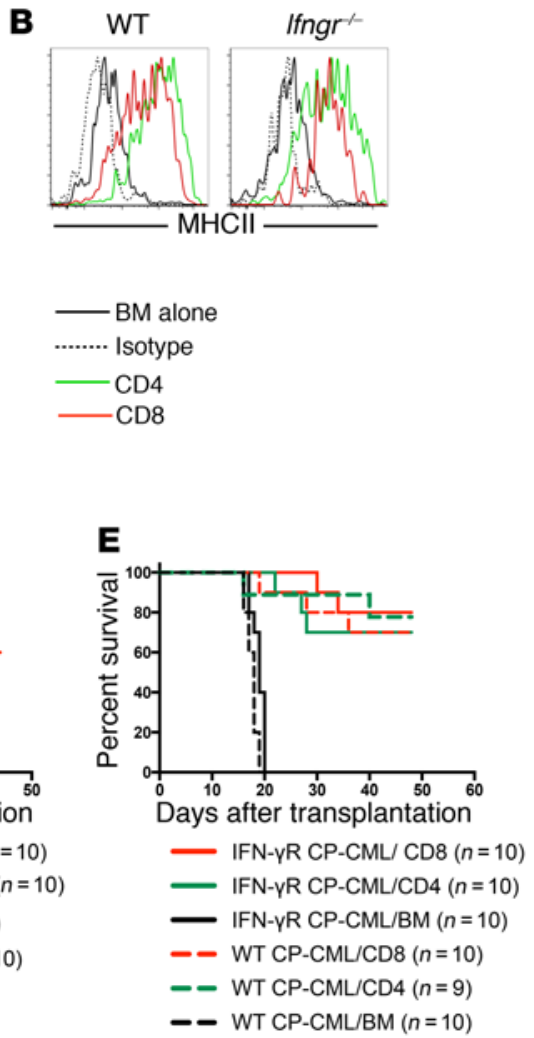

H

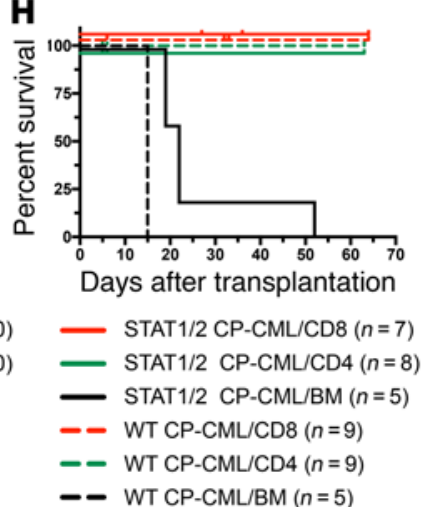

Figure 2. The IFN- $\gamma \mathrm{R}$ on $\mathrm{mBC}-\mathrm{CML}$ cells is required for GVH-induced MHC upregulation and effective CD4- and CD8-mediated GVL, whereas MHCII upregulation on MCP-CML cells and GVL are independent of both the IFN- $\gamma R$ and IFNAR1 and STAT1/STAT2. (A) Irradiated B6 mice were reconstituted with C3H.SW BM and B6 Ifngr ${ }^{-/,}$, B6 Ifnar $^{-1-}$, or control WT B6 mBCCML cells, with no C3H.SW T cells or C3H.SW CD4 or CD8 cells. MHCI and $\mathrm{MHCll}$ upregulation did not occur on Ifngr ${ }^{-/-}$mBC-CML LSCs but was intact on Ifnar1 ${ }^{-/-}$LSCs. (B) Mice were transplanted as in A, except with B6 WT or Ifngr ${ }^{-1-}$ mCP-CML cells. MHCII upregulation was similar in WT and gene-deficient mCP-CML LSCs. Consistent with the upregulation data, IFN- $\gamma \mathrm{R}$ mBC-CML was resistant to CD4- and CD8-mediated CVL in the $\mathrm{C} 3 \mathrm{H} . \mathrm{SW} \rightarrow \mathrm{B} 6$ model (C) and to CD8-mediated $\mathrm{GVL}$ in the BALB/C $\rightarrow \mathrm{B} 6$ model (D). In contrast, Ifngr ${ }^{-1-} \mathrm{mCP}-\mathrm{CML}$ (E), Ifnart ${ }^{-/-} \mathrm{mBC}-\mathrm{CML}(\mathbf{F})$, Ifngr ${ }^{-1}$ Ifnar1 ${ }^{-/-}$(double-KO [DKO]) mCPCML (C), and Stat1 ${ }^{-/-}$Stat2 $^{-/-}$ mCP-CML (H) cells were GVL sensitive. Experiments shown in $\mathbf{E}-\mathbf{H}$ were in the $\mathrm{C} 3 \mathrm{H} . \mathrm{SW} \rightarrow \mathrm{B} 6$ model. AR1, IFNAR1 ${ }^{-1-} . P<0.006$, comparing any $\mathrm{WT} \mathrm{MBC}-\mathrm{CML}$ or IFNAR mBC-CML CD4 or CD8 recipient group with its $\mathrm{BM}$-alone control; $P<0.002$, comparing any $\mathrm{MCP}-\mathrm{CML} \mathrm{T}$ cell recipient group with its $\mathrm{BM}$-alone control. $P$ values determined by 2-tailed Mann-Whitney $U$ test. pendently of TCR interactions with MHC on MBC-CML or mCPCML LSCs. Consistent with this, donor $\mathrm{CD}^{+} \mathrm{T}$ cells induced MHCII upregulation on MHCI-deficient ( $\beta$-2-microglobulindeficient, referred to herein as $\left.32 \mathrm{~m}^{-/}\right) \mathrm{B} 6 \mathrm{mBC}-\mathrm{CML}$ and $\mathrm{mCP}-$ CML, and CD4 cells induced MHCI upregulation on MHCIIdeficient B6 mBC-CML cells (Figure 1, C and D). To further investigate the requirement of TCR-MHC interactions for MHC upregulation, we asked whether donor-strain $\mathrm{MCP}-\mathrm{CML}$ cells in mice undergoing a GVH response would upregulate MHCII. Irradiated $\mathrm{BALB} / \mathrm{c}$ mice were reconstituted with $\mathrm{B} 6 \mathrm{BM}$ and $\mathrm{B} 6 \mathrm{mCP}-\mathrm{CML}$ cells, with or without $\mathrm{B} 6 \mathrm{CD} 4$ or $\mathrm{CD} 8$ cells. In this design, donor $\mathrm{T}$ cells are activated by host BALB/c cells, but because the $\mathrm{T}$ cells are syngeneic with the $\mathrm{B} 6 \mathrm{mCP}-\mathrm{CML}$, they do not mediate GVL and presumably do not have high-avidity TCR-MHC interactions with them. In line with data using MHC-deficient mCP-CML, we observed that MHCII was upregulated on donor $\mathrm{mCP}-\mathrm{CML}$
LSCs in GVH mice relative to LSCs in mice that did not receive donor T cells (Figure 1E).

MHCII ${ }^{h i}$ mBC-CML cells can serially transplant leukemia. To determine whether LSC-phenotype cells induced to express MHCII have functional properties of LSCs, we sort purified $\mathrm{MHCII}^{\mathrm{hi}} \mathrm{CD} 11 \mathrm{~b}^{-}$and $\mathrm{MHCII}^{\mathrm{lo}} \mathrm{CD} 11 \mathrm{~b}^{-} \mathrm{mBC}-\mathrm{CML}$ cells from mice undergoing a GVH response and transferred them into sublethally irradiated syngeneic $\mathrm{B} 6$ mice. Both $\mathrm{MHCII}^{\mathrm{lo}}$ and $\mathrm{MHCII}^{\text {hi }} \mathrm{mBC}$ CML cells transferred $\mathrm{mBC}-\mathrm{CML}$, but the progeny of $\mathrm{MHCII}^{\mathrm{hi}}$ cells lost MHCII expression (Figure $1 \mathrm{~F}$ ), indicating that MHCII upregulation was transient.

Role of IFNs in leukemia MHC upregulation and GVL. IFNs upregulate MHC on many cell types. To test the role of IFNs in GVH-induced MHC upregulation on $\mathrm{mBC}-\mathrm{CML}$ cells, we created type I IFN receptor-deficient (Ifnar1 $1^{-/}$) and IFN- $\gamma \mathrm{R}-$ deficient (Ifngr/-) $\mathrm{mBC}-\mathrm{CML}$. Whereas MHC upregulation 
A

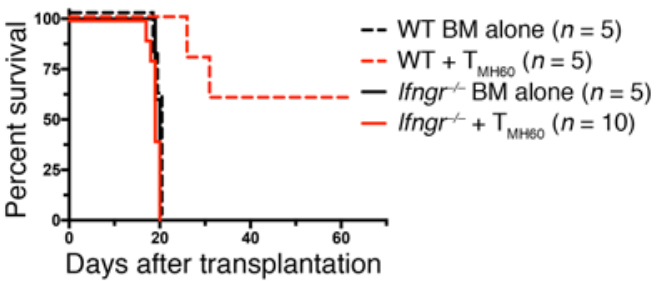

C

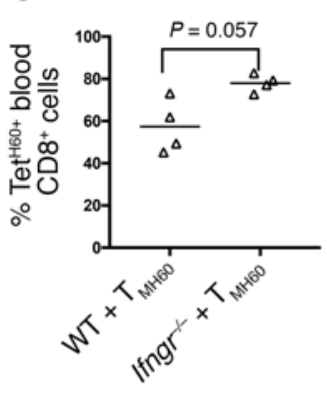

D

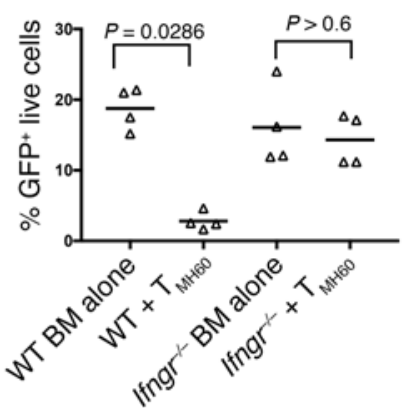

B

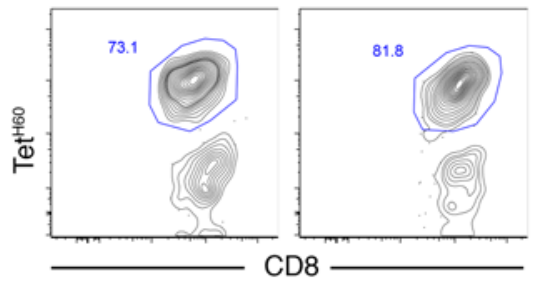

E

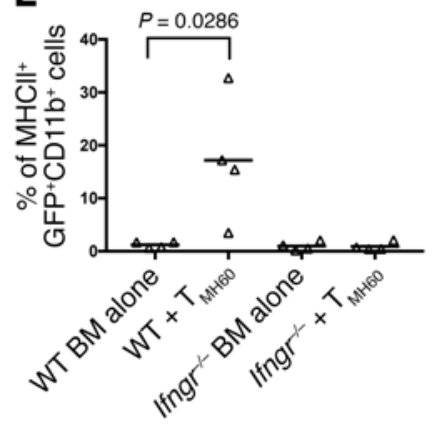

$\mathbf{F}$

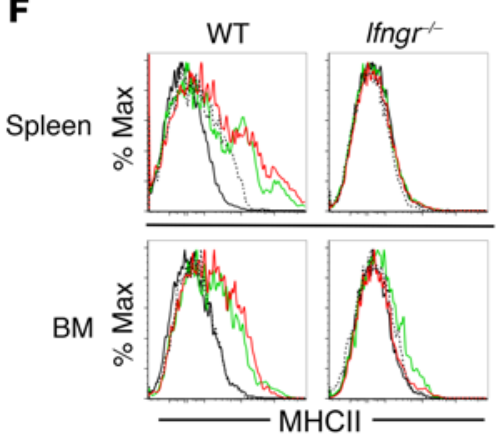

G

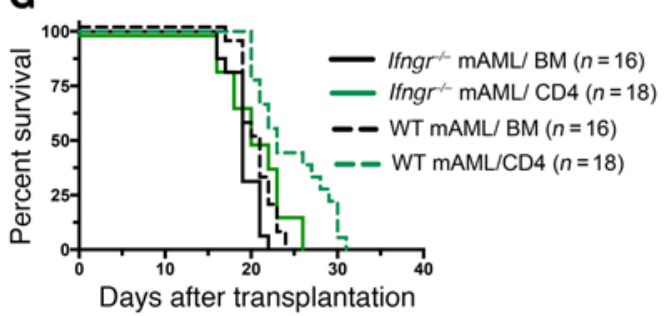

Figure 3. IFN- $\gamma$ stimulation is required for $\mathrm{T}_{\text {MH60 }}$-mediated $\mathrm{GVL}$ against $\mathrm{H6O}^{+} \mathrm{mBC}-\mathrm{CML}$ and CD4- and CD8-mediated CVL against MLL-AF9-induced AML. (A-E). Irradiated

B6. $\mathrm{H} 60$ mice were reconstituted with $\mathrm{C} 3 \mathrm{H}$. SW BM, WT or Ifngr ${ }^{-1-B 6 . H 60 ~ m B C-C M L, ~}$ with no T cells or with and $5 \times 10^{4}$ sort-purified $\mathrm{CD} 8{ }^{+} \mathrm{CD} 44^{+}$cells from $\mathrm{H} 60$-vaccinated donors, which contained 3,500 $\mathrm{Tet}^{\mathrm{H} 60+}$ cells. (A) Post-transplantation survival. (B) Representative $\mathrm{Tet}^{\mathrm{H} 60}$ staining of blood CD8 cells from WT and Ifngr ${ }^{-1-} \mathrm{H} \mathrm{O}^{+} \mathrm{mBC}-\mathrm{CML}$ recipients and their quantitation (C) on day 14 after transplantation. The percentage of blood NGFR+EGFP+ ${ }^{+}$cells on day 14 after transplantation and the percentage of these cells that were $\mathrm{MHCll}^{+}$are shown in $\mathbf{D}$ and $\mathbf{E}$, respectively. For $\mathbf{C}-\mathbf{E}$, each symbol represents data from an individual mouse; horizontal lines represent the mean. $P=0.0034$, comparing survival of recipients of WT H60 $\mathrm{BC}-\mathrm{CML}$, with or without $\mathrm{T}_{{ }_{M H 60}}$. $P=0.378$, comparing survival of recipients of Ifngr ${ }^{-1} \mathrm{H} 60^{+} \mathrm{mBC}-\mathrm{CM}$ with or without $\mathrm{T}_{\text {MH60 }}$ (F-H) Irradiated B6 mice were reconstituted with C3H.SW BM, WT or Ifngr ${ }^{-1-}$ MLL-AF9 AML with no T cells, or with $\mathrm{C} 3 \mathrm{H}$. SW CD4 or CD8 cells. Spleen and BM cells were harvested on day 13 after transplantation and analyzed for MLL-AF9 AML (GFP+) MHCIl expression (F). Survival for CD4-mediated and CD8-mediated GVL is shown in $\mathbf{G}$ and $\mathbf{H}$, respectively. $P \leq 0.0016$, comparing the survival in the WT $\mathrm{mAML} B M$-alone group with WT CD4 or CD8 recipients; $P=0.024$, comparing $/ \mathrm{fngr}^{-/} \mathrm{BM}$ alone with CD4 recipients; $P=0.0079$ and $P=0.0053$, comparing $\mathrm{CD} 4$ and $\mathrm{CD} 8$ recipients of WT versus Ifngr ${ }^{-1}$ MLL-AF9 AML, respectively. $P$ values determined by 2-tailed MannWhitney $U$ test. Data in $\mathbf{G}$ and $\mathbf{H}$ were combined from 2 repetitions.

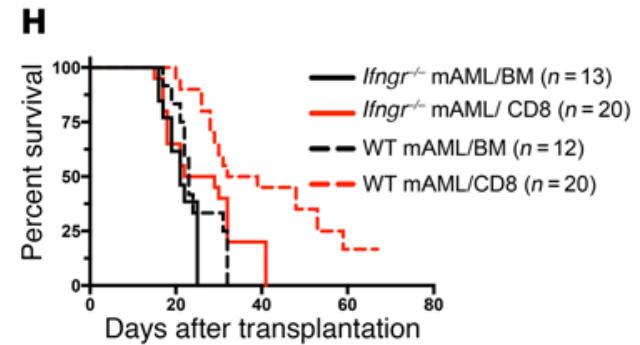

was intact in Inar1 $^{-/-} \mathrm{mBC}-\mathrm{CML}$ cells, we found that it was completely abrogated in Ifngr ${ }^{-1} \mathrm{mBC}-\mathrm{CML}$ cells (Figure 2A). In contrast, MHCII upregulation was similar in WT and Ifngr ${ }^{-1}$ $\mathrm{mCP}-\mathrm{CML}$ LSCs harvested from GVH mice (Figure 2B). Strikingly, consistent with the MHC upregulation data, Ifngr ${ }^{-/} \mathrm{mBC}-$ CML was completely resistant to CD4- and CD8-mediated GVL in the $\mathrm{C} 3 \mathrm{H} . \mathrm{SW} \rightarrow \mathrm{B} 6$ strain pairing (Figure $2 \mathrm{C}$ ), whereas Ifnar $1^{-/-} \mathrm{mBC}-\mathrm{CML}$, Ifngr ${ }^{--} \mathrm{mCP}-\mathrm{CML}$, Ifngr ${ }^{-/}$Ifnar1 $1^{-/}$, and Stat1 $^{-1}$ Stat2 $^{-/-}$mCP-CML were as GVL sensitive as their WT counterparts (Figure 2, E-H). It was unexpected that Ifngr-/mBC-CML was completely resistant to CD8-mediated GVL as there is substantial basal MHCI expression that is only modestly increased with IFN- $\gamma$ stimulation. We considered the possibility that there is a dominant, targeted minor histocompatibility antigen (miHA) that depends on IFN- $\gamma$ for its generation and presentation. We therefore performed a GVL experiment in the
$\mathrm{BALB} / \mathrm{c}\left(\mathrm{H}-2^{\mathrm{d}}\right) \rightarrow \mathrm{B} 6 \mathrm{MHC}-\mathrm{mismatched}$ system, in which it would be unlikely that $\mathrm{CD} 8$ alloimmunity would rely on a single miHA. Even with an MHCI mismatch, IFN- $\gamma \mathrm{R}^{-/-} \mathrm{mBC}-\mathrm{CML}$ was completely resistant to CD8-mediated GVL (Figure 2D), suggesting that IFN- $\gamma$ sensitization of $\mathrm{mBC}-\mathrm{CML}$ cells to CD8-mediated GVL involves more than MHCI upregulation.

We also compared the GVL effect against WT and Ifngr$\mathrm{mBC}-\mathrm{CML}$ mediated by memory $\mathrm{T}$ cells raised against the miHA $\mathrm{H} 60(26,29,30)$. C3H.SW mice $\left(\mathrm{H}_{60}\right)$ were vaccinated against $\mathrm{H} 60$ as previously reported (26). B6.H60 mice (congenic for H60) were irradiated and reconstituted with C3H.SW BM, with WT or Ifngr/- B6.H60 mBC-CML with no T cells, or with $5 \times 10^{4}$ sortpurified $\mathrm{CD}^{+} \mathrm{CD} 44^{+}$cells from $\mathrm{H} 60$-vaccinated mice $\left(\mathrm{T}_{\mathrm{MH} 60}\right)$ containing 3,500 H60-reactive cells as determined by $\mathrm{H} 60$ tetramer staining ( $\mathrm{Tet}^{\mathrm{H} 60}$; data not shown). Ifngr/- B6.H60 mBCCML was highly GVL resistant (Figure 3A, survival), despite an 
A

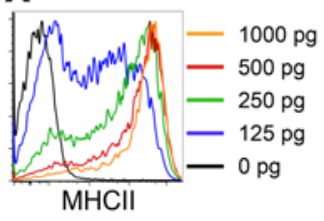

C

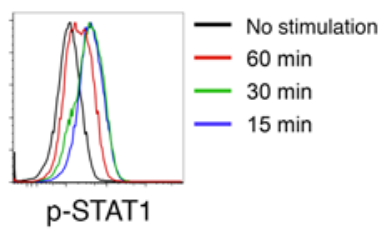

B

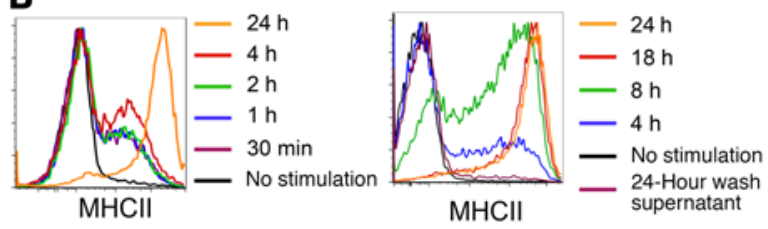

D

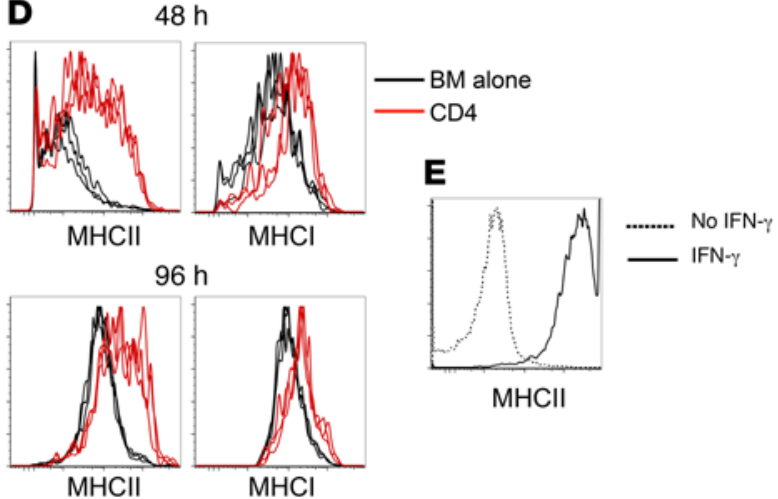

Figure 4. In vitro IFN- $\gamma$ treatment is sufficient to upregulate MHCII on mBC-CML LSCs. (A) Sort-purified $\mathrm{mBC}-\mathrm{CML}$ LSCs were continuously cultured with graded concentrations of IFN- $\gamma$, and $\mathrm{MHCII}$ expression was measured 72 hours later. (B) mBC-CML LSCs were cultured for 30 minutes to 24 hours in IFN- $\gamma(200 \mathrm{pg} / \mathrm{ml})$ Stimulated cells were washed extensively and then further cultured without IFN- $\gamma$ for a total culture time of 72 hours, followed by measurement of MHCIl expression. The final supernatant from each wash was cultured with fresh mBC-CML cells for 72 hours, and MHCII was not upregulated (see "24-Hour wash supernatant" in B). Data are representative of 2 experiments, with 3 replicates per condition. (C) mBC-CML cells were cultured in IFN- $\gamma$, and p-STAT1 was measured by flow cytometry at the indicated times. (D) Irradiated B6 mice were reconstituted with C3H.SW BM with or without C3H.SW CD4 cells. On day 7 after alloBMT, sort-purified $\mathrm{mBC}-\mathrm{CML}$ LSCs were injected. $\mathrm{mBC}-\mathrm{CML}$ cells were recovered 48 and 96 hours later and $\mathrm{MHCl}$ and $\mathrm{MHCIl}$ expression was analyzed by flow cytometry. Shown are data from splenic $\mathrm{mBC}-\mathrm{CML}$ cells; data in BM were similar (not shown). Each line represents data from an individual mouse. (E) Irradiated B6 mice were transplanted with $\mathrm{mBC}-\mathrm{CML}$ cells, C3H.SW BM, and CD4 cells. On day 21 after transplantation, sort-purified splenic MHCII- CD116- mBC-CML cells were cultured with or without IFN- $\gamma$ for 72 hours. IFN- $\gamma$ induced MHCII expression.

expansion of H60-reactive $\mathrm{T}$ cells in blood that was at least as strong as that observed in recipients of WT B6.H60 mBC-CML (Figure 3, B and C). Whereas $\mathrm{T}_{\mathrm{MH} 60}$ reduced blood WT B6.H60 $\mathrm{mBC}-\mathrm{CML}$ cells, they failed to do the same against Ifngr $/-\mathrm{B} 6 . \mathrm{H} 60$ mBC-CML (Figure 3D). Finally, H60-reactive CD8 cells induced MHCII upregulation (a marker for IFN- $\gamma$ stimulation) only on WT B6.H60 mBC-CML cells (Figure 3E).

To determine whether the reliance on IFN- $\gamma$ stimulation for effective GVL is unique to $\mathrm{mBC}-\mathrm{CML}$ or is a more general property of myeloblastic leukemias, we created WT and Ifngr/- AML by transducing WT or Ifngr $` \mathrm{BM}$ with a retrovirus encoding the MLL-AF9 translocation (27) and then tested the sensitivities of these AML cells to CD4- and CD8-mediated GVL in the C3H.SWgB6 model. Cohorts were sacrificed 12 days after BMT for analysis of MHC expression on splenic and BM AML cells. CD4 and CD8 cells induced a modest upregulation of MHCII on WT AML cells but not on Ifngr/- AML cells (Figure 3F). MHCI was not upregulated (date not shown). Importantly, compared with WT MLL-AF9, we found that Ifngr/- MLL-AF9 mAML was relatively resistant to both $\mathrm{CD} 4$ - and CD8-mediated GVL (Figure 3, $\mathrm{G}$ and $\mathrm{H}$ ).

IFN- $\gamma$ is sufficient to upregulate MHC on $m B C-C M L$ cells. While the IFN- $\gamma \mathrm{R}$ was required for $\mathrm{MHC}$ upregulation on $\mathrm{MBC}-\mathrm{CML}$ cells in vivo, it was possible that other unidentified stimuli were also required. To test whether IFN- $\gamma$ alone is sufficient, we examined the effects of IFN- $\gamma$ on mBC-CML cells in vitro. Culture in media plus IFN- $\gamma$, but not media alone, induced MHCII upregulation. With continuous culture in IFN- $\gamma$ at concentrations detected in the serum of GVHD mice (31), MHCII upregulation was not detected until 24 to 48 hours and usually peaked between 48 and 72 hours (Figure $4 \mathrm{~A}$ and data not shown). An IFN- $\gamma$ pulse of as short as 1 hour induced MHCII upregulation on a minority of cells at 72 hours, but maximum MHCII upregulation required exposure for 8 to 18 hours (Figure $4 \mathrm{~B}$ ). Despite this requirement, in vitro IFN- $\gamma$ stimulation induced MBC-CML STAT1 phosphorylation within 15 minutes (Figure 4C), indicating that, despite rapid STAT1 phosphorylation, more prolonged IFN- $\gamma \mathrm{R}$ signaling is required for maximal MHCII upregulation. To determine whether the in vitro time course of MHCII upregulation parallels what occurs in vivo, we transferred B6 $\mathrm{MHCII}^{\mathrm{lo}} \mathrm{mBC}-\mathrm{CML}$ cells harvested from sublethally irradiated syngeneic B6 mice into irradiated B6 mice that were transplanted with C3H.SW BM, with or without C3H.SW CD4 cells, 7 days earlier. We observed that MHCI and MHCII expression increased on splenic (Figure 4D) and BM (not shown) mBC-CML LSCs in GVH mice at 48 and 96 hours after transfer, but not in mice that did not receive $\mathrm{CD} 4$ cells.

These results identify a key mechanism that at least in part explains the resistance of $\mathrm{MBC}-\mathrm{CML}$ and AML GVL against GVL compared with the GVL that develops against CP-CML. Effective GVL against $\mathrm{mBC}-\mathrm{CML}$ and mAML requires sufficient and sustained IFN- $\gamma$ to sensitize LSCs to T cell killing, whereas effective GVL against $\mathrm{mCP}-\mathrm{CML}$ does not require IFN- $\gamma$ stimulation . $\mathrm{mBC}$ CML LSCs recovered from mice that were dying from leukemia at later times after transplantation, despite being transplanted with donor T cells, were mostly MHCII ${ }^{\mathrm{l}}$. This decline in MHCII expression was not due to selection for cells that could not respond to IFN- $\gamma$, as $\mathrm{MHCII}^{\mathrm{lo}}$ cells harvested from mice with progressive $\mathrm{mBC}-\mathrm{CML}$, despite receiving donor $\mathrm{T}$ cells, uniformly upregulated MHCII in vitro with IFN- $\gamma$ stimulation (Figure 4E). This suggests that leukemia progression at later points after transplantation is due to both a contraction of the alloreactive $\mathrm{T}$ cell response and a drop in IFN- $\gamma$ levels.

$m B C-C M L$ and $m C P-C M L$ gene expression changes in the GVH environment. To better understand potential mechanisms of action of IFN- $\gamma$, we performed gene expression analyses on WT and Ifngr/- $\mathrm{mBC}-\mathrm{CML}$ and WT $\mathrm{mCP}-\mathrm{CML}$ LSCs sorted from mice that were or were not undergoing a GVH response. For $\mathrm{mBC}-\mathrm{CML}$ LSCs, irradiated B6 mice were reconstituted with WT or Ifngr ${ }^{-1}$ 


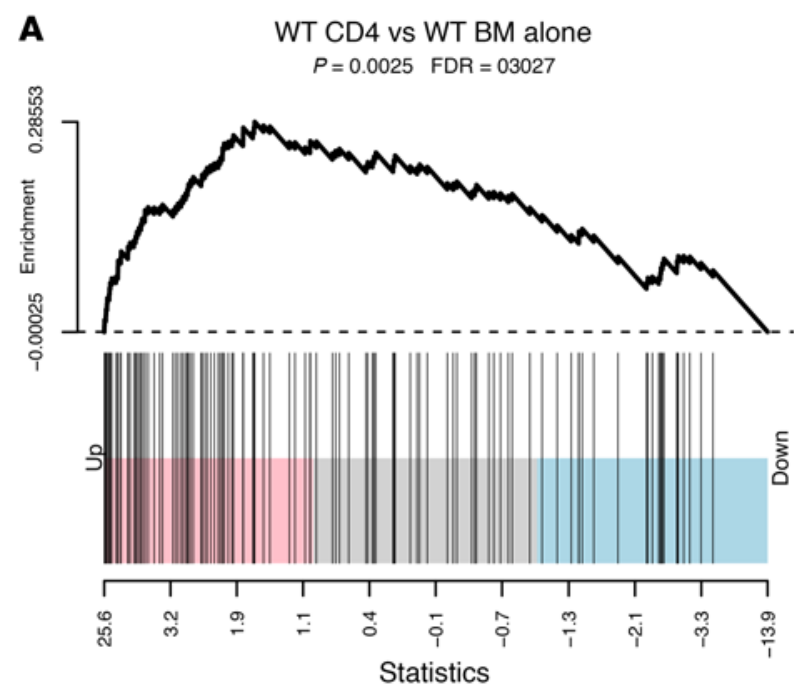

B
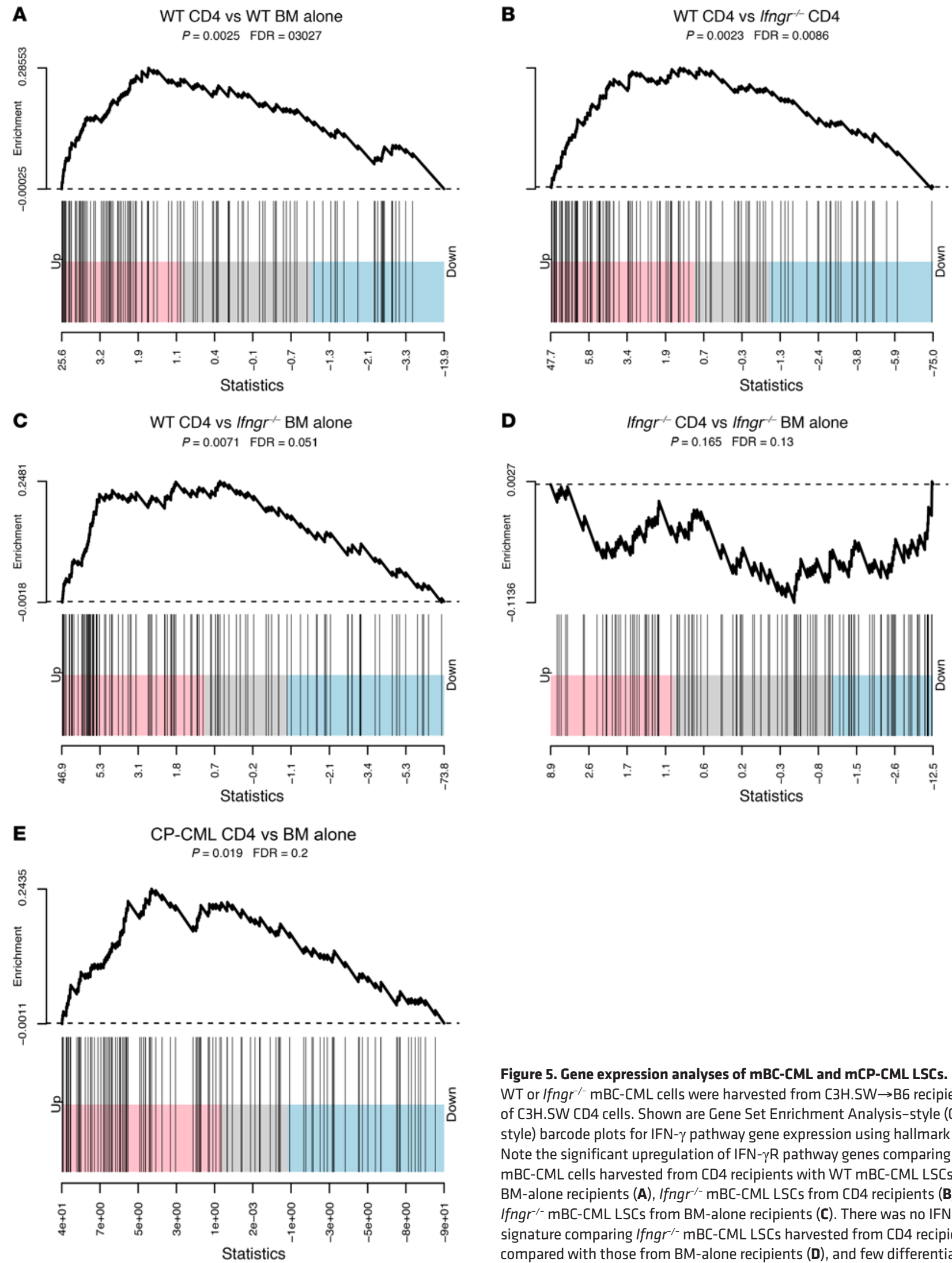

Figure 5. Gene expression analyses of $\mathrm{mBC}-\mathrm{CML}$ and $\mathrm{mCP}-\mathrm{CML}$ LSCs. (A-D) WT or Ifngr ${ }^{-1} \mathrm{mBC}-\mathrm{CML}$ cells were harvested from $\mathrm{C} 3 \mathrm{H} . \mathrm{SW} \rightarrow \mathrm{B} 6$ recipients of C3H.SW CD4 cells. Shown are Gene Set Enrichment Analysis-style (CSEAstyle) barcode plots for IFN- $\gamma$ pathway gene expression using hallmark data. Note the significant upregulation of IFN- $\gamma \mathrm{R}$ pathway genes comparing WT $\mathrm{mBC}-\mathrm{CML}$ cells harvested from CD4 recipients with WT mBC-CML LSCs from BM-alone recipients (A), Ifngr ${ }^{-1-} \mathrm{mBC}-\mathrm{CML}$ LSCs from CD4 recipients (B), and Ifngr ${ }^{-1-} \mathrm{mBC}-\mathrm{CML}$ LSCs from BM-alone recipients (C). There was no IFN- $\gamma \mathrm{R}$ signature comparing Ifngr ${ }^{-1} \mathrm{mBC}-\mathrm{CML}$ LSCs harvested from $\mathrm{CD} 4$ recipients compared with those from BM-alone recipients (D), and few differentially expressed genes distinguished these groups (Supplemental Figure 1). (E) WT B6 mCP-CML LSCs were harvested from BALB/c recipients that did or did not receive CD4 cells (BM alone). An IFN- $\gamma$ R signature was observed in RNA from LSCs harvested from CD4 recipients as compared to RNA from LSCs from BM alone controls. 
mBC-CML cells, C3H.SW T cell-depleted BM, with or without C3H.SW CD4 cells. For mCP-CML, to facilitate recovery of sufficient $\mathrm{mCP}-\mathrm{CML}$ cells, we again used the B6gBALB/c GVH system with $\mathrm{B} 6 \mathrm{mCP}-\mathrm{CML}$ cells, with or without $\mathrm{B} 6 \mathrm{CD} 4$ cells. $\mathrm{mBC}$ CML and LSK MCP-CML cells (lin') were harvested between days 12 and 14 after BMT. LSCs from 3 individual mice were analyzed from each group.

We saw a clear IFN- $\gamma$ gene signature when comparing mRNA from Ifngr/- $\mathrm{mBC}$-CML cells from the BM-alone group with mRNA from WT $\mathrm{mBC}-\mathrm{CML}$ cells harvested from $\mathrm{CD} 4$ recipients (Figure 5). Relative to the Ifngr/- groups, there was a background IFN- $\gamma$ signature in WT mBC-CML cells harvested from the B6 BM-alone group, probably due to IFN- $\gamma$ produced by the host-versus-graft response. In addition to a classic IFN- $\gamma$ signature, in WT BC-CML cells from GVH mice, we observed changes in genes linked to antigen presentation, ubiquitination, proteasome function, and apoptosis. As expected, there was no IFN- $\gamma$ signature in the IFN- $\gamma$ R mBC-CML cells. By volcano plot analysis, we found that gene expression was similar in Ifngr/- $\mathrm{mBC}$-CML LSCs harvested from the BM-alone and CD4 groups, and pathway analyses were unrevealing as to what drove the few observed differences (data not shown).

$m C P-C M L$ gene expression analysis. We also detected an IFN- $\gamma$ signature in $\mathrm{mCP}-\mathrm{CML}$ LSCs harvested from $\mathrm{CD} 4$ recipients relative to LSCs harvested from mice treated with BM alone (Supplemental Figure 1; supplemental material available online with this article; https://doi.org/10.1172/JCI85736DS1). Therefore, the fact that WT $\mathrm{mCP}-\mathrm{CML}$ and Ifngr/- $\mathrm{mCP}-\mathrm{CML}$ were equivalently GVL sensitive was not due to WT MCP-CML being unresponsive to IFN- $\gamma$.

$T$ cells are the critical source of IFN- $\gamma$. T cells are the major, but not exclusive, producers of IFN- $\gamma$. To determine whether donor T cell-derived IFN- $\gamma$ is required for MHC upregulation and GVL, we compared $\mathrm{mBC}-\mathrm{CML}$ MHC upregulation and GVL in recipients of WT or IFN- $\gamma$-deficient CD $4^{+}$T cells. Because TCR-MHC interactions were not required for MHC upregulation, we also considered the possibility that $\mathrm{T}$ cells unable to directly kill leukemia cells could provide IFN- $\gamma$ in trans, thereby rescuing the inability of IFN- $\gamma$-deficient T cells to mediate GVL. Irradiated B6 mice were reconstituted with $\mathrm{B} 6 \mathrm{~B}^{2} \mathrm{~m}^{-/} \mathrm{mBC}-\mathrm{CML}\left(\mathrm{MHCI}^{-}\right)$ and BALB/c BM with: a) no T cells; b) WT or IFN- $\gamma$-deficient BALB/c CD4 cells; or c) WT or IFN- $\gamma$-deficient CD4 cells with WT or IFN- $\gamma$-deficient BALB/c CD 8 cells. $B 2 \mathrm{~m}^{-/-} \mathrm{mBC}-\mathrm{CML}$ was used to prevent donor CD8 cells from directly killing leukemia cells. Whereas WT CD4 cells induced MHCII expression and reduced the number of splenic and $\mathrm{BM} \mathrm{mBC}-\mathrm{CML}$ cells by day 14 after BMT, IFN- $\gamma$-deficient CD 4 cells failed to do so (Figure 6, $\mathrm{A}-\mathrm{C}$, and data not shown), indicating that donor $\mathrm{T}$ cell-derived IFN- $\gamma$ is critical. The addition of WT, but not IFN- $\gamma$-deficient, CD8 cells restored IFN- $\gamma$-induced MHCII upregulation and diminished the number of $\mathrm{MBC}-\mathrm{CML}$ cells in spleen and $\mathrm{BM}$ by day 14 (Figure 6, A-C, and not shown), indicative of a GVLpromoting effect. Consistent with this early GVL effect, the addition of WT, but not IFN- $\gamma$-deficient, CD8 cells to IFN- $\gamma$-deficient CD 4 cells prolonged the survival of mice in 2 of 3 repeated experiments (Figure 6D). The rescue of IFN- $\gamma$-deficient CD 4 cells by WT CD 8 cells may have been incomplete because of differences in the kinetics and magnitude of IFN- $\gamma$ production by CD 4 and CD8 cells, which is consistent with the lower mean fluorescence intensity (MFI) of MHCII in the IFN- $\gamma$-deficient CD4 plus WT CD8 group (mean of 443 vs. 167). That the addition of WT CD8 cells to IFN- $\gamma$-deficient CD4 cells restored GVL also confirms that the inability of IFN- $\gamma$-deficient CD 4 cells to mediate GVL was not due to a failure to generate cytolytic effectors.

$I F N-\gamma$ alone is insufficient for GVL. Given the complete GVL resistance of Ifngr ${ }^{-/} \mathrm{mBC}$-CML, we considered the possibility that IFN- $\gamma$ alone has direct and meaningful antileukemia activity. Arguing against this is that for effective GVL, CD4 and CD8 cells require leukemia expression of MHCII and MHCI, respectively $(10,11,24)$ despite alloreactive $\mathrm{T}$ cells activated in response to recipient alloantigens generating substantial IFN- $\gamma$. However, sufficiently high local IFN- $\gamma$ levels may only be achieved when IFN- $\gamma$-producing T cells make cognate TCR-MHC contacts. To test this hypothesis, we engineered a situation in which cognate TCR-MHC interactions occurred, but perforin and death receptor-dependent $\mathrm{T}$ cellinduced apoptosis and necroptosis were prevented. We first created Fas (TNFRSF6) via Fas-associated protein with death domain (Fadd ${ }^{-/}$Ripk3 $^{-/-}$) mBC-CML cells. FADD is required for all death receptor signaling; however, $\mathrm{Fadd}^{-/-}$mice are embryonically lethal unless they are crossed with Ripk3-- mice due to the role of FADD in inhibiting RIPK3-dependent necroptosis (32). We then compared GVL mediated by WT or perforin ${ }^{-/}$CD 4 or CD 8 cells against Fadd ${ }^{-/-}$ Ripk3 $^{-/-}$and control Fadd ${ }^{+/-}$Ripk3 $^{+/-}$mBC-CML. Effective GVL only required either WT T cells or FADD/RIPK3-intact $\mathrm{MBC}$-CML (Figure 7). In contrast, GVL was completely abrogated when donor $\mathrm{T}$ cells were perforin ${ }^{-/}$and $\mathrm{mBC}-\mathrm{CML}$ cells were $\mathrm{Fadd}^{-/} \mathrm{Ripk3}^{-/-}$, despite T cells being capable of producing IFN- $\gamma$ and making TCRMHC contacts with $\mathrm{mBC}-\mathrm{CML}$ cells. Therefore, CD4- and CD8dependent GVL depends on T cell perforin and/or $\mathrm{MBC}-\mathrm{CML}$ death receptor signaling, and T cell-derived IFN- $\gamma$ alone is insufficient.

\section{Discussion}

Relapsed acute leukemia after alloSCT remains a major unmet medical need. Much of the early and exciting efficacy of alloSCT as a form of adoptive $\mathrm{T}$ cell immunotherapy was observed in patients with CP-CML (33); however, in the tyrosine kinase inhibitor era, these patients infrequently undergo transplantation. While GVL is active against myeloblastic leukemias, it is less potent than GVL against CP-CML. This difference in potency is reflected in the higher rates of BC-CML and AML relapse after alloSCT. Unfortunately, there has been little progress in decreasing or treating relapses, in which the withdrawal of immunosuppression and donor leukocyte infusions infrequently result in durable remissions. A major barrier to progress has been a lack of understanding of the resistance mechanisms. A central paradox, evident since the early days of clinical alloSCT, is why an alloimmune response sufficient to cause GVHD, promote $100 \%$ donor hematopoietic chimerism, and mediate GVL against $\mathrm{CP}-\mathrm{CML}$ is so much less effective against AML. Here, we report a mechanism that may explain this: the alloimmune $\mathrm{T}$ cell response against AML and BC-CML must generate sufficient IFN- $\gamma$ to sensitize myeloblast LSCs to T cell killing. In contrast, a smaller and more smoldering alloreactive response, which does not generate high levels of IFN- $\gamma$, is sufficient for GVL against MCP-CML and for GVHD.

Ifngr ${ }^{-1-} \mathrm{mBC}-\mathrm{CML}$ and MLL-AF9 mAML were GVL resistant, and, conversely, IFN- $\gamma$-deficient $\mathrm{T}$ cells mediated no GVL against $\mathrm{mBC}-\mathrm{CML}$, despite their expansion and induction 
A

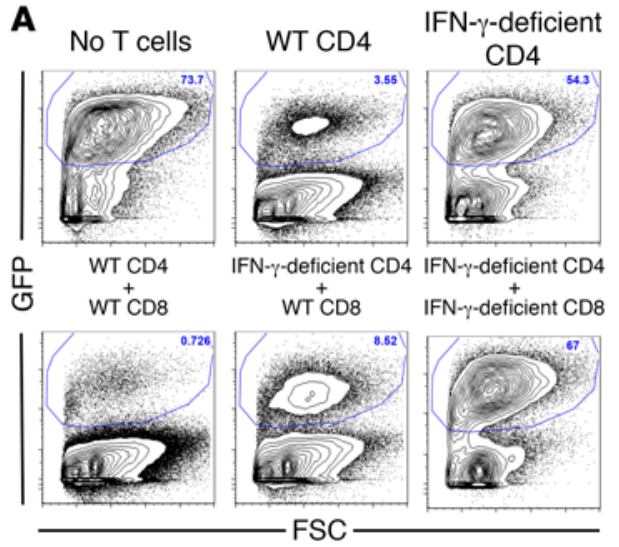

C

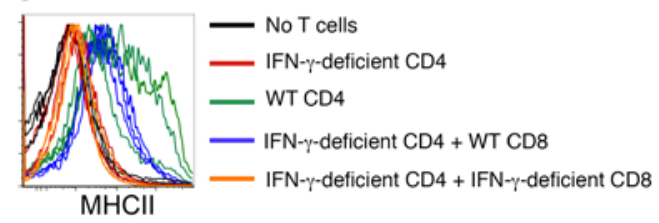

B

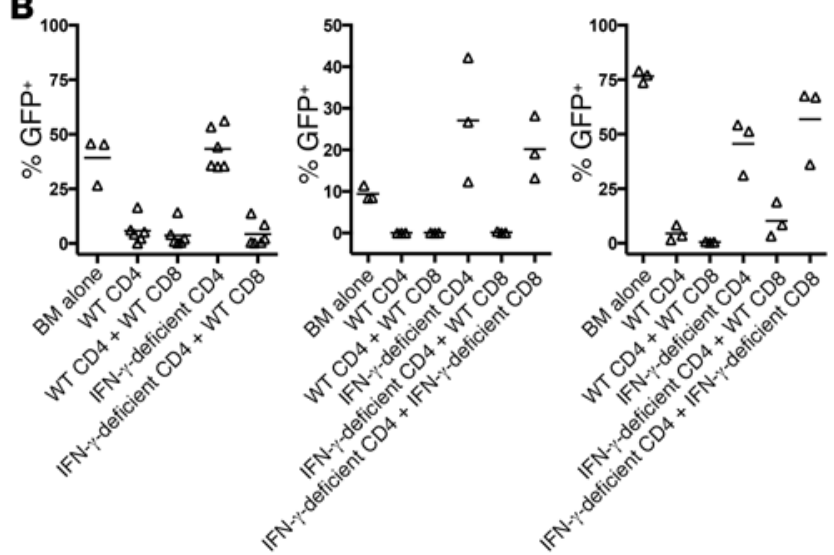

D

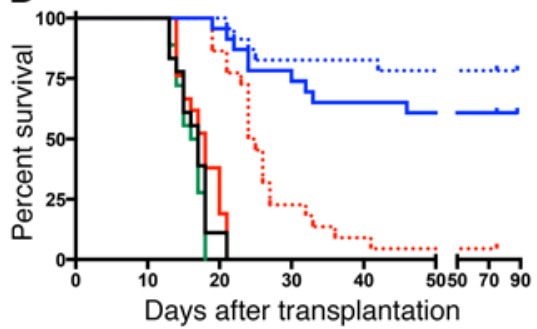

ᄂ $\mathrm{BM}(n=18)$

1 WT CD4 $(n=23)$

- ᄂ . WT CD $4+$ WT CD8 $(n=23)$

1 IFN- $\gamma$-deficient CD4 $(n=21)$

- L . IFN- $\gamma$-deficient CD4 + WT CD8 $(n=22)$

1. IFN- $\gamma$-deficient CD4 + IFN- $\gamma$-deficient CD8 $(n=18)$

Figure 6. T cell-derived IFN- $\gamma$ delivered in cis or in trans is required for CD4-mediated GVL. Irradiated B6 mice were reconstituted with BALB/C BM and B6 $B 2 \mathrm{~m}^{-/-} \mathrm{mBC}-\mathrm{CML}$ with no T cells or with the following BALB/c background T cells: (i) WT CD4 cells; (ii) IFN- $\gamma$-deficient CD4 cells; (iii) WT CD4 cells plus WT CD8 cells; (iv) IFN- $\gamma$-deficient CD4 cells plus WT CD8 cells; or (v) IFN- $\gamma$-deficient CD4 cells plus IFN- $\gamma$-deficient CD8 cells. Cohorts were sacrificed 10-14 days after transplantation, and $\mathrm{mBC}-\mathrm{CML}$ cells were analyzed by flow cytometry. (A) Representative flow cytometry from splenocytes. (B) Percentage of leukemic splenocytes from individual mice ( $n=3$ independent experiments). Each symbol represents data from an individual mouse; horizontal lines indicate mean values. (C) Upper panel: WT, but not IFN- $\gamma$-deficient, CD4 or CD8 cells induced MHCII upregulation on mBC-CML LSCs. The upper panel shows LSC MHCII expression. Each line represents data from an individual mouse. Lower panel: Percentage of LSCs that were $\mathrm{MHCII}^{+}$from 2 of 3 experiments. Each symbol represents data from an individual mouse; horizontal lines indicate the mean values. Insufficient numbers of LSCs were present to analyze in the third experiment (see bottom panel in Figure 5B). (D) In 2 of 3 experiments, the addition of WT CD8 cells, but not IFN- $\gamma$-deficient CD8 cells, to IFN- $\gamma$-deficient CD4 cells prolonged survival (data were combined from 2 experiments). $P=0.0037$ comparing the KO CD4 + WT CD8 group to either the KO CD4 or KO CD4 + KO CD8 groups.

of clinical GVHD (data not shown). In mouse models without immunosuppression, there is an early wave of IFN- $\gamma$ production coincident with rapid alloreactive $\mathrm{T}$ cell expansion (34-36). However, in clinical alloSCT, in which pharmacologic immunosuppression is given, such a rise in IFN- $\gamma$ may only infrequently occur, and this may in part contribute to the more global GVL resistance of myeloblastic leukemias. Chronic GVHD (cGVHD) has been associated with a lower risk for AML relapse, and recent data suggest that CGVHD is associated with the action of IFN $-\gamma(37)$. Perhaps the sustained IFN- $\gamma$ associated with cGVHD contributes to GVL, along with alloreactive cytolytic T cells. In contrast, GVL against mCP-CML was independent of type I and II IFNs or their downstream signaling components STAT1 and
STAT2, even though gene expression analysis indicated that mCP-CML LSCs are IFN- $\gamma$ responsive.

In an effort to understand the cell-intrinsic properties of $\mathrm{mBC}$ CML cells that render them GVL resistant relative to CP-CML cells, we have tested in GVL models mouse blast crisis and chronic phase leukemias deficient in numerous genes including those encoding B2M, MHCII, Fas, TRAIL, TNFR1/R2, PD-L1, PD-L2, ICAM-1, and IFNAR1 $(10,11,24,25)$. Until the present study, we found no deficiency that selectively diminished GVL against $\mathrm{MBC}$-CML without equivalently reducing GVL against $\mathrm{mCP}-\mathrm{CML}$.

Other factors in addition to the requirement for IFN- $\gamma \mathrm{R}$ signaling may also contribute to the relative GVL resistance of myeloblastic leukemias as compared with that of CP-CML. Nonetheless, the 
A

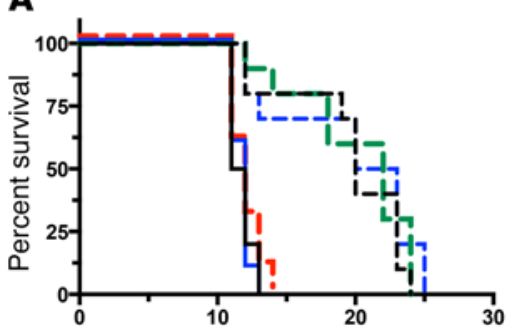

Days after transplantation

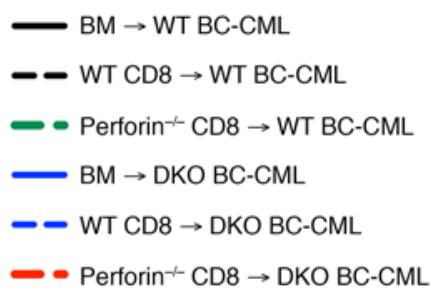

B

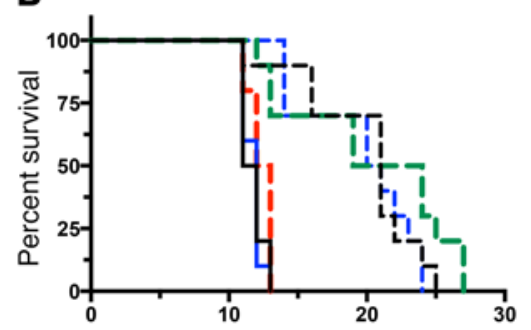

Days after transplantation

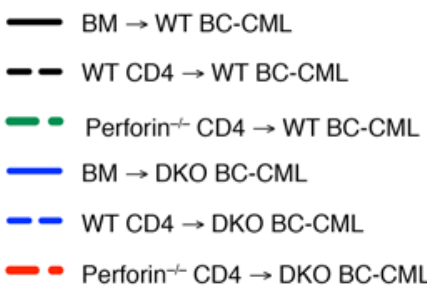

Figure 7. CD4 and CD8-mediated GVL require intact T cell perforin or leukemia FADD/RIPIK3, and T cell-derived IFN- $\gamma$ alone is insufficient for GVL. Irradiated B6 mice were reconstituted with BALB/c BM and B6 Fadd ${ }^{-/-}$Ripk3 $^{-/-}$(DKO) or control B6 Fadd ${ }^{+/-}$Ripk3 $^{+/-}$mBC-CML (WT) with no BALB/c T cells or with WT or perforin ${ }^{-1-}$ CD8 cells $(\mathbf{A})$ or CD4 cells (B). Data show survival rates from 1 of 2 similar experiments with 10 mice per group. $P<0.0003$, comparing any WT or DKO BM-alone group with any WT T cell group. $P>0.07$, comparing DKO BM-alone versus perforin ${ }^{-1-}$ CD4 or CD8 groups. $P$ values determined by 2 -tailed Mann-Whitney $U$ test.

present results argue that GVL could be meaningfully augmented by exposing malignant myeloblasts to IFN- $\gamma$ after transplantation, timed to coincide with the presence of alloreactive cytolytic T cells. The key translational question is how to achieve this. IFN- $\gamma$-induced MHC upregulation and GVL sensitization do not require TCR-MHC contacts between IFN- $\gamma$-producing T cells and leukemia cells (see Figures 1 and 5). That is, IFN- $\gamma$ can be delivered to leukemia cells in trans by $\mathrm{T}$ cells that do not target the leukemia cells. This suggests a feasible clinical strategy. CMV reactivation early after transplantation and the use of CMV seropositive donors have been associated with lower rates of AML relapse (38-41). CMV reactivation induces the expansion of CMV-reactive T cells and $\mathrm{NKG}_{2} \mathrm{C}^{+} \mathrm{NK}$ cells (42), both of which can produce IFN- $\gamma$ and raise serum IFN- $\gamma$ levels (43). Although other explanations are possible, our data suggest that anti-CMV immune responses could be promoting GVL through the elaboration of IFN- $\gamma$. Approaches to further promote the anti-CMV immune response, perhaps by donor and recipient anti-CMV vaccination $(44,45)$, might augment GVL without an increase in GVHD. This strategy is analogous to our use of IFN- $\gamma$-positive CD8 cells to promote GVL by IFN- $\gamma$-deficient CD 4 cells.

That IFN- $\gamma$ was required for CD4-mediated GVL is easy to understand, given its importance in upregulating MHCII. However, it was surprising that Ifngr/ $\mathrm{mBC}-\mathrm{CML}$ and MLL-AF9 mAML were resistant to CD8-mediated GVL, as these leukemias are $\mathrm{MHCI}^{+}$at baseline, and IFN- $\gamma$-induced MHCI upregulation is modest or does not occur in the case of MLL-AF9 AML. It is possible that MHCI upregulation crosses a threshold of MHCI-miHA peptide complexes to sufficiently engage alloreactive T cells. However, the fact that Ifngr ${ }^{--} \mathrm{mBC}-\mathrm{CML}$ was also resistant to CD8mediated GVL in the MHC-mismatched setting argues against this being the sole explanation, considering the much higher frequency of T cells that recognize allogeneic MHC $(46,47)$ and the diminished likelihood that GVL in this model would rely on a single targeted peptide. IFN- $\gamma$ upregulates ICAM-1 (data not shown), immunoproteasome components, and chemokines that attract $\mathrm{T}$ cells and modifies pro- and antiapoptotic pathways (Figure 5 and ref. 48), all of which could promote effective CD8 cell killing. Discovering precisely how IFN- $\gamma \mathrm{R}$ signaling sensitizes $\mathrm{mBC}-\mathrm{CML}$ and $\mathrm{AML}$ cells to killing will require substantial further investigation, and given the pleiotropic effects of IFN- $\gamma \mathrm{R}$ signaling, it is possible that no single downstream mechanism will explain its dominant role. Another intriguing and unanswered question is what sig$\mathrm{nal}(\mathrm{s})$ in the alloimmune environment induce MHCII upregulation on mCP-CML LSCs. Given that TCR-MHC interactions are also not required, a soluble factor is most likely responsible.

We used $\mathrm{Fadd}^{-/}$Ripk3-/- $\mathrm{mBC}-\mathrm{CML}$ and perforin $^{-/-} \mathrm{T}$ cells to demonstrate that, despite IFN- $\gamma$ being critical for GVL, alone it is insufficient, as there was no GVL when T cells lacked perforin and leukemias lacked FADD and RIPK3. These data also highlight the idea that cytolytic pathways engaged by both CD4 and CD8 cells are redundant, in that either perforin or death receptor FADD/RIPK3-dependent killing is sufficient for GVL.

We studied models of CP-CML, BC-CML, and AML, which share essential genetic and phenotypic features with their human counterparts (49). It will be important to determine the importance of IFN- $\gamma$ in GVL against other mouse myeloid leukemias and against human AML samples. Available data suggest that IFN- $\gamma$ could broadly impact GVL against human AML. Human AML stem cells include $\mathrm{MHCII}^{-}$cells (50), and acute promyelocytic AML is classically $\mathrm{MHCII}^{-}$. Other leukemias reported to be $\mathrm{MHCII}^{+}$usually have cell populations that are $\mathrm{MHCII}^{-}$, as the MHCII expression threshold for calling an AML $\mathrm{MHCII}^{+}$does not require all cells to express MHCII (5154). Therefore, if alloreactive CD4 cells are to directly mediate GVL against these $\mathrm{MHCII}^{-}$cells, MHCII expression must be induced. Primary human AML cells and AML-like cell lines express the IFN- $\gamma \mathrm{R}$ and are IFN- $\gamma$ responsive $(48,55-62)$, with both basal and IFN- $\gamma$-induced STAT1 phosphorylation (58) and MHCI and MHCII upregulation. We hope our results demonstrating a critical role for IFN- $\gamma$ in GVL responses against two clinically relevant mouse models of myeloblastic leukemias will both stimulate a broader evaluation of the IFN- $\gamma$ responsiveness of additional mouse AML models and of human AML specimens classified by molecular features, and the development of approaches to safely deliver IFN- $\gamma$ in the clinic.

\section{Methods}

\section{Mice}

C57BL6 (B6; $\left.\mathrm{H}-2^{\mathrm{b}}\right)$ and BALB/c $\left(\mathrm{H}-2^{\mathrm{d}}\right)$ mice were purchased from Harlan Laboratories. C3H.SW mice were purchased from The Jack- 
son Laboratory and bred at Yale University. IFN- $\gamma$-deficient (63) and perforin $^{-/}$mice backcrossed with BALB/c mice $(64,65)$ were bred at the University of Iowa and at Yale University. Ifngr ${ }^{-/}$mice were purchased from the Jackson Laboratory. Ifnar1 $1^{-/-}$mice were obtained from H. Rosenberg (66) (National Cancer Institute [NCI], Bethesda, Maryland, USA) and bred at Yale University. Ifnar1 ${ }^{-/-}$Ifngr $^{-/-}$mice were obtained from William Klimstra (University of Pittsburgh School of Medicine, Pittsburgh, Pennsylvania, USA). Stat ${ }^{-/-}$Stat $^{-/-}$mice were obtained from John Alcorn (University of Pittsburgh). B6.H60 mice were originally obtained from Derry Roopenian (The Jackson Laboratory) and were bred at the University of Pittsburgh. B6 Fadd ${ }^{-/}$Ripk3 $^{-1-}$ and control B6 Fadd ${ }^{-/+}$Ripk3 $^{-/+}$mice were maintained at St. Jude Children's Research Hospital (Memphis, Tennessee, USA) (32).

\section{Leukemia induction}

$\mathrm{mBC}-\mathrm{CML}$ and $\mathrm{mCP}-\mathrm{CML}$ were created as previously described $(11,12)$. Briefly, mBC-CML was created by spin-infection of BM from 5FU-treated mice with two MSCV2.2-based retroviruses, one expressing BCR-ABL (along with a truncated and nonsignaling human nerve growth factor receptor [NGFR]) and a second expressing NUP98 and HOXA9 (coexpressing GFP) (11). MLL-AF9 AML was induced by transduction with an MSCV2.2-based retrovirus encoding the MLL-AF9 fusion cDNA and GFP (27) (gift of Scott Armstrong, Memorial Sloan Kettering Institute, New York, New York, USA). Cells were passaged in vivo and frozen. For each experiment $\mathrm{mCP}-\mathrm{CML}$ was created by spin-infection with BCR-ABL retrovirus alone as described previously (24).

\section{BMT}

Four different strain pairings were used in alloBMT experiments. All irradiation was delivered by a cesium irradiator. All BM was T cell depleted and is referred to herein as BM.

C3H.SW $\left(H-2^{b}\right) \rightarrow B 6\left(H-2^{b}\right)$. B6 mice received 900 cGy irradiation and were reconstituted with $5 \times 10^{6}$ to $7 \times 10^{6} \mathrm{C} 3 \mathrm{H}$.SW BM, with or without bead-purified C3H.SW CD4 or CD8 cells.

C3H.SW $\rightarrow$ B6.H6O. B6.H60 mice received 900cGy irradiation and were reconstituted with $7 \times 10^{6} \mathrm{C} 3 \mathrm{H}$.SW BM cells and CD8 ${ }^{+} \mathrm{CD} 44^{+}$ cells from C3H.SW mice vaccinated against $\mathrm{H} 60$ as previously described (26).

$B A L B / C\left(H-2^{d}\right) \rightarrow B 6$. B6 mice were irradiated (900 cGy) and reconstituted with $10^{7} \mathrm{BALB} / \mathrm{c}$ BM cells, with or without purified $\mathrm{BALB} / \mathrm{c}$ (WT or gene-deficient) CD4 or CD8 cells.

$B 6 \rightarrow B A L B / c$. Irradiated BALB/c mice (900 cGy) were reconstituted with $10^{7} \mathrm{~B} 6 \mathrm{BM}$ cells, with or without purified B6 CD4 or CD8 cells. $\mathrm{mBC}-\mathrm{CML}$ and AML cells were either from frozen stocks or fresh cells harvested from sublethally irradiated B6 mice seeded 14 to 21 days beforehand. Two hundred micrograms anti-NK1.1 (PKC136; lab-prepared) was given i.p. on days -2 and -1 in experiments with the $\mathrm{BALB} / \mathrm{c} \rightarrow \mathrm{B} 6$ strain pair and on days $-2,-1$, and +7 in experiments with $\beta 2 \mathrm{M}^{-/-} \mathrm{mBC}-\mathrm{CML}$ to prevent NK cell-mediated killing of $\mathrm{MHCI}^{-}$or $\mathrm{H}-2^{\mathrm{d}+\mathrm{b}-}$ cells.

\section{Antibodies and flow cytometry}

mCP-CML LSCs were identified by excluding lin ${ }^{+}$cells using staining with biotin-conjugated antibodies against TER-119, Gr-1, CD19, and CD11b (all from BD Pharmingen; clones TER-119, RB6-8C5, 1D3, and M1/70, respectively); CD4 and CD8 (clones GK1.5 and
TIB120; lab-prepared); CD117 phycoerythrin (PE) and Sca-1 FITC (BD Pharmingen; clones 2B8 and Ly-6a/E); and anti-NGFR Alexa 647 (clone HB8737; lab-prepared). mBC-CML cells (lin-) could be identified by only staining for CD11b. Staining for $\mathrm{K}^{\mathrm{b}}$ and I-A/I-E (MHCII) was done with clones AF6-88.5 and M5/114.15.2, respectively (BioLegend). Phosphorylated STAT1 (p-STAT1) staining was performed with or without IFN- $\gamma$ stimulation, followed by fixation in $2 \%$ paraformaldehyde in PBS. The cells were permeabilized in BD Phosflow Perm Buffer III for 30 minutes on ice, washed twice in BD Pharmingen Stain Buffer, and stained with PE-conjugated p-STAT1 antibody (pY701; BD). H60-reactive T cells, which detect the LTFNYRNL peptide bound to $\mathrm{K}^{\mathrm{b}}$, were identified by MHCI tetramer staining $\left(\mathrm{Tet}^{\mathrm{H} 60+}\right)$. H6O tetramers were created at the NIH's tetramer facility (Atlanta, Georgia, USA).

\section{Cell purifications}

Lymph node (LN) and splenic cells were prepared as previously described (11). T cell purifications were performed using EasySep negative selection reagents according to the manufacturer's instructions (STEMCELL Technologies). Cell purities were greater than $88 \%$, with less than $2 \%$ of contaminating CD 4 or CD8 cells. CD8 memory T cells were isolated from $\mathrm{H} 60$-vaccinated mice by first using a CD8 EasySep negative selection kit. Cells were then stained with antibodies against CD8 and CD44, followed by sorting on a FACSAria cell sorter (BD Biosciences).

\section{In vitro $\mathrm{mBC}-\mathrm{CML}$ stimulation}

Splenocytes from sublethally irradiated $\mathrm{B} 6$ mice injected with $\mathrm{mBC}$ CML cells approximately 2 to 3 weeks earlier (at least $80 \% \mathrm{EGFP}^{+}$ $\mathrm{NGFR}^{+}$) were cultured for different lengths of time in DMEM with $10 \%$ FCS with graded amounts of IFN- $\gamma$ (Peprotech). In experiments in which IFN- $\gamma$ was removed and cells were recultured, cells were washed 4 times in $50 \mathrm{cc}$ of media. The final supernatant was cultured with fresh $\mathrm{mBC}-\mathrm{CML}$ cells for another 72 hours as a confirmation that IFN- $\gamma$ had been removed. At the end of the culture period, cells were more than $80 \%$ viable.

\section{Gene expression profiling}

$m C P-C M L$. Irradiated $\mathrm{BALB} / \mathrm{c}$ mice were reconstituted with $\mathrm{B} 6 \mathrm{BM}$, $7 \times 10^{5}$ BCR-ABL spin-infected B6 BM (see leukemia induction) with no B6 T cells, or with $5 \times 10^{5}$ B6 CD4 cells. On day 12 after BMT, $\mathrm{NGFR}^{+}$LSK cells were separately sorted from the spleens of 3 individual mice from each group.

$m B C-C M L$. Irradiated $\mathrm{B} 6$ mice were reconstituted with $\mathrm{C} 3 \mathrm{H}$. SW BM, B6 WT or Ifngr ${ }^{-/} \mathrm{mBC}-\mathrm{CML}$, with no T cells, or with $4 \times 10^{6}$ C3H.SW CD 4 cells. On day 14 after BMT, lin ${ }^{-} \mathrm{BBC}-\mathrm{CML}$ cells were sorted from the spleens of 3 individual mice from each group. RNA was isolated using a QIAGEN RNA Extraction Kit, followed by library preparation using an Epicentre kit. Expression was analyzed by quantitation using an Illumina WG-6 v2.0 Expression BeadChip. Differential expression was computed using the Bioconductor package (67), and pathway analysis was performed using the limma "camera" function (68), which controls for intercorrelation among genes, and the "canonical pathways" gene sets provided by mSigDB (69).

\section{Statistics}

Survival differences were calculated using the log-rank test (MantelCox) (GraphPad Prism; GraphPad Software version 7). In some 
CD8-mediated GVL against mCP-CML experiments, some mice reached predetermined criteria for sacrifice due to GVHD. If spleens were small and the most recent analysis of peripheral blood showed, at most, only a few $\mathrm{NGFR}^{+} \mathrm{CP}-\mathrm{CML}$ cells, these mice were scored as having GVHD and were censored (see Figure 2, G and H). Differences in cell percentages were determined by 2-tailed Mann-Whitney $U$ test.

\section{Study approval}

All animal studies were approved by the Yale University School of Medicine IACUC and the University of Pittsburgh School of Medicine IACUC.

\section{Author contributions}

CMM designed and executed experiments, analyzed data, and created figures. JL and MZ designed and executed experiments. WDS designed experiments, analyzed data, created figures, and wrote the manuscript. MC analyzed gene expression data. DRG provided intellectual input and provided key reagents. JTH provided key reagents.

\section{Acknowledgments}

This work was supported by NIH grants R01 HL117855 and NIH R01CA09643. We also thank the excellent staff of the Yale Animal Resources Center.

Address correspondence to: Warren D. Shlomchik, Thomas E. Starzl Biomedical Science Tower, Room E1552, 200 Lothrop Street, Pittsburgh, Pennsylvania 15261, USA. Phone: 412.624.5322; Email:warrens@pitt.edu.

CMM's present address is: Department of Medicine, Yale University School of Medicine, New Haven, Connecticut, USA.
1. Vincent K, Roy DC, Perreault C. Nextgeneration leukemia immunotherapy. Blood. 2011;118(11):2951-2959.

2. Blazar BR, Murphy WJ, Abedi M. Advances in graft-versus-host disease biology and therapy. Nat Rev Immunol. 2012;12(6):443-458.

3. Markey KA, MacDonald KP, Hill GR. The biology of graft-versus-host disease: experimental systems instructing clinical practice. Blood. 2014;124(3):354-362.

4. Shlomchik WD. Graft-versus-host disease. Nat Rev Immunol. 2007;7(5):340-352.

5. Alyea EP, et al. NCI First International Workshop on The Biology, Prevention and Treatment of Relapse after Allogeneic Hematopoietic Cell Transplantation: report from the committee on prevention of relapse following allogeneic cell transplantation for hematologic malignancies. Biol Blood Marrow Transplant. 2010;16(8):1037-1069.

6. Collins RH Jr, et al. Donor leukocyte infusions in 140 patients with relapsed malignancy after allogeneic bone marrow transplantation. J Clin Oncol. 1997;15(2):433-444.

7. McGlave P. Bone marrow transplants in chronic myelogenous leukemia: an overview of determinants of survival. Semin Hematol. 1990;27(3 suppl 4):23-30.

8. Sawyers CL, et al. Imatinib induces hematologic and cytogenetic responses in patients with chronic myelogenous leukemia in myeloid blast crisis: results of a phase II study. Blood. 2002;99(10):3530-3539.

9. Matte CC, et al. Donor APCs are required for maximal GVHD but not for GVL. Nat Med. 2004;10(9):987-992.

10. Matte-Martone C, Liu J, Jain D, McNiff J, Shlomchik WD. $\mathrm{CD}^{+}$but not $\mathrm{CD} 4^{+} \mathrm{T}$ cells require cognate interactions with target tissues to mediate GVHD across only minor $\mathrm{H}$ antigens, whereas both $\mathrm{CD}^{+}$and $\mathrm{CD} 8^{+} \mathrm{T}$ cells require direct leukemic contact to mediate GVL. Blood. 2008;111(7):3884-3892.

11. Matte-Martone C, et al. Graft-versus-leukemia (GVL) against mouse blast-crisis chronic myelogenous leukemia (BC-CML) and chronic-phase chronic myelogenous leukemia (CP-CML): shared mechanisms of $\mathrm{T}$ cell killing, but programmed death ligands render $\mathrm{CP}-\mathrm{CML}$ and not BC-CML GVL resistant. J Immunol. 2011;187(4):1653-1663.

12. Pear WS, et al. Efficient and rapid induction of a chronic myelogenous leukemia-like myeloproliferative disease in mice receiving P210 bcr/abl-transduced bone marrow. Blood. 1998;92(10):3780-3792.

13. Li S, Ilaria RL Jr, Million RP, Daley GQ, Van Etten RA. The P190, P210, and P230 forms of the $\mathrm{BCR} / \mathrm{ABL}$ oncogene induce a similar chronic myeloid leukemia-like syndrome in mice but have different lymphoid leukemogenic activity. JExp Med.1999;189(9):1399-1412.

14. Dash AB, et al. A murine model of CML blast crisis induced by cooperation between $\mathrm{BCR} / \mathrm{ABL}$ and NUP98/HOXA9. Proc Natl Acad Sci U S A. 2002;99(11):7622-7627.

15. Neering SJ, et al. Leukemia stem cells in a genetically defined murine model of blast-crisis CML. Blood. 2007;110(7):2578-2585.

16. Borrow J, et al. The $\mathrm{t}(7 ; 11)(\mathrm{p} 15 ; \mathrm{p} 15)$ translocation in acute myeloid leukaemia fuses the genes for nucleoporin NUP98 and class I homeoprotein HOXA9. Nat Genet. 1996;12(2):159-167.

17. Nakamura T, et al. Fusion of the nucleoporin gene NUP98 to HOXA9 by the chromosome translocation $\mathrm{t}(7 ; 11)(\mathrm{p} 15 ; \mathrm{p} 15)$ in human myeloid leukaemia. Nat Genet. 1996;12(2):154-158.

18. Yamamoto K, Nakamura Y, Saito K, Furusawa S. Expression of the NUP98/HOXA9 fusion transcript in the blast crisis of Philadelphia chromosome-positive chronic myelogenous leukaemia with $\mathrm{t}(7 ; 11)$ (p15;p15). Br J Haematol. 2000;109(2):423-426.

19. Ahuja HG, Popplewell L, Tcheurekdjian L, Slovak ML. NUP98 gene rearrangements and the clonal evolution of chronic myelogenous leukemia. Genes Chromosomes Cancer. 2001;30(4):410-415.

20. Nakamura T, Yamazaki Y, Hatano Y, Miura I. NUP98 is fused to PMX1 homeobox gene in human acute myelogenous leukemia with chromosome translocation $\mathrm{t}(1 ; 11)$ (q23;p15). Blood. 1999;94(2):741-747.

21. Wong KF, So CC, Kwong YL. Chronic myelomonocytic leukemia with $\mathrm{t}(7 ; 11)(\mathrm{p} 15 ; \mathrm{p} 15)$ and NUP98/HOXA9 fusion. Cancer Genet Cytogenet.
1999;115(1):70-72.

22. Hussey DJ, Dobrovic A. Recurrent coiled-coil motifs in NUP98 fusion partners provide a clue to leukemogenesis. Blood. 2002;99(3):1097-1098.

23. Huntly BJ, Gilliland DG. Leukaemia stem cells and the evolution of cancer-stem-cell research. Nat Rev Cancer. 2005;5(4):311-321.

24. Matte CC, et al. Graft-versus-leukemia in a retrovirally induced murine CML model: mechanisms of T-cell killing. Blood. 2004;103(11):4353-4361.

25. Zheng $\mathrm{H}$, et al. Effector memory $\mathrm{CD} 4^{+} \mathrm{T}$ cells mediate graft-versus-leukemia without inducing graft-versus-host disease. Blood. 2008;111(4):2476-2484.

26. Li N, et al. Memory T cells from minor histocompatibility antigen-vaccinated and virus-immune donors improve GVL and immune reconstitution. Blood. 2011;118(22):5965-5976.

27. Krivtsov AV, et al. Transformation from committed progenitor to leukaemia stem cell initiated by MLL-AF9. Nature. 2006;442(7104):818-822.

28. Huntly BJ, et al. MOZ-TIF2, but not BCR-ABL, confers properties of leukemic stem cells to committed murine hematopoietic progenitors. Cancer Cell. 2004;6(6):587-596.

29. Wang X, Roopenian D, Martone C, Li N, Li H, Shlomchik WD. Mechanisms of crosspresentation in graft-vs-host disease. Blood. 2009;114(22):687.

30. Choi EY, et al. Immunodominance of H6O is caused by an abnormally high precursor $\mathrm{T}$ cell pool directed against its unique minor histocompatibility antigen peptide. Immunity. 2002;17(5):593-603.

31. Li H, et al. Graft-versus-host disease is independent of innate signaling pathways triggered by pathogens in host hematopoietic cells. J Immunol. 2011;186(1):230-241.

32. Dillon CP, et al. RIPK1 blocks early postnatal lethality mediated by caspase- 8 and RIPK3. Cell. 2014;157(5):1189-1202

33. Horowitz MM, et al. Graft-versus-leukemia reactions after bone marrow transplantation. Blood. 1990;75(3):555-562.

34. Teshima T, et al. Acute graft-versus-host disease does not require alloantigen expression on host epithelium. Nat Med. 2002;8(6):575-581. 
35. Hill GR, Crawford JM, Cooke KR, Brinson YS, Pan L, Ferrara JL. Total body irradiation and acute graft-versus-host disease: the role of gastrointestinal damage and inflammatory cytokines. Blood.1997;90(8):3204-3213.

36. Li H, et al. Graft-versus-host disease is independent of innate signaling pathways triggered by pathogens in host hematopoietic cells. J Immunol. 2011;186(1):230-241.

37. Hakim FT, et al. Upregulation of IFN-iducible and damage-response pathways in chronic graft-versus-host disease. JImmunol. 2016;197(9):3490-3503.

38. Nachbaur D, Clausen J, Kircher B. Donor cytomegalovirus seropositivity and the risk of leukemic relapse after reduced-intensity transplants. Eur J Haematol. 2006;76(5):414-419.

39. Elmaagacli AH, et al. Early human cytomegalovirus replication after transplantation is associated with a decreased relapse risk: evidence for a putative virus-versus-leukemia effect in acute myeloid leukemia patients. Blood. 2011;118(5):1402-1412.

40. Lönnqvist B, Ringdèn O, Ljungman P, Wahren B, Gahrton G. Reduced risk of recurrent leukaemia in bone marrow transplant recipients after cytomegalovirus infection. Br J Haematol. 1986;63(4):671-679.

41. Green ML, et al. CMV reactivation after allogeneic HCT and relapse risk: evidence for early protection in acute myeloid leukemia. Blood. 2013;122(7):1316-1324.

42. Foley B, et al. Cytomegalovirus reactivation after allogeneic transplantation promotes a lasting increase in educated NKG2C+ natural killer cells with potent function. Blood. 2012;119(11):2665-2674.

43. Rhodes-Feuillette A, Canivet M, Champsaur H, Gluckman E, Mazeron MC, Peries J. Circulating interferon in cytomegalovirus infected bone-marrow-transplant recipients and in infants with congenital cytomegalovirus disease. J Interferon Res. 1992;Spec No:91-98.

44. Griffiths PD, et al. Cytomegalovirus glycoprotein-B vaccine with MF59 adjuvant in transplant recipients: a phase 2 randomised placebo-controlled trial. Lancet. 2011;377(9773):1256-1263.

45. Plotkin SA, et al. Effect of Towne live virus vaccine on cytomegalovirus disease after renal transplant. A controlled trial. Ann Intern Med. 1991;114(7):525-531.

46. Aosai F, et al. Different types of allospecific CTL clones identified by their ability to recognize peptide loading-defective target cells. Eur J Immunol. 1991;21(11):2767-2774.

47. Crumpacker DB, Alexander J, Cresswell P, Engelhard VH. Role of endogenous peptides in murine allogenic cytotoxic $\mathrm{T}$ cell responses assessed using transfectants of the antigen-processing mutant $174 x$ CEM.T2. JImmunol. 1992;148(10):3004-3011.

48. Varela N, Munoz-Pinedo C, Ruiz-Ruiz C, Robledo G, Pedroso M, López-Rivas A. Interferon-gamma sensitizes human myeloid leukemia cells to death receptor-mediated apoptosis by a pleiotropic mechanism. JBiol Chem. 2001;276(21):17779-17787.

49. Sykes DB, et al. Inhibition of dihydroorotate dehydrogenase overcomes differentiation blockade in acute myeloid leukemia. Cell. 2016;167(1):171-186.e15.

50. Blair A, Hogge DE, Sutherland HJ. Most acute myeloid leukemia progenitor cells with long-term proliferative ability in vitro and in vivo have the phenotype CD34(+)/CD71(-)/HLA-DR'. Blood. 1998;92(11):4325-4335.

51. Syampurnawati M, et al. DR negativity is a distinctive feature of M1/M2 AML cases with NPM1 mutation. Leuk Res. 2008;32(7):1141-1143.

52. Syampurnawati M, et al. HLA-DR-negative AML (M1 and M2): FLT3 mutations (ITD and D835) and cell-surface antigen expression. Leuk Res. 2007;31(7):921-929.

53. Kussick SJ, et al. A distinctive nuclear morphology in acute myeloid leukemia is strongly associated with loss of HLA-DR expression and FLT3 internal tandem duplication. Leukemia. 2004;18(10):1591-1598

54. Wetzler M, et al. HLA-DR antigen-negative acute myeloid leukemia. Leukemia. 2003;17(4):707-715

55. Oliveira G, et al. Modeling antileukemic adoptive immunotherapy in mouse-humans chimeras to identify novel mechanisms of cancer immunoediting. Blood. 2013;122(21):2017.

56. Nguyen S, et al. HLA-E upregulation on IFN- $\gamma$ activated AML blasts impairs CD94/NKG2Adependent NK cytolysis after haplo-mismatched hematopoietic SCT. Bone Marrow Transplant. 2009;43(9):693-699.

57. Eljaafari A, et al. Alloreaction increases or restores CD40, CD54, and/or HLA molecule expression in acute myelogenous leukemia blasts, through secretion of inflammatory cytokines: Dominant role for TNF $\beta$, in concert with IFN $\gamma$. Leukemia. 2006;20(11):1992-2001.
58. Irish JM, et al. Single cell profiling of potentiated phospho-protein networks in cancer cells. Cell. 2004;118(2):217-228.

59. Mizuno S, Emi N, Kasai M, Ishitani A, Saito H. Aberrant expression of HLA-G antigen in interferon $\gamma$-stimulated acute myelogenous leukaemia. Br J Haematol. 2000;111(1):280-282.

60. Munker R, Andreeff M. Induction of death (CD95/FAS), activation and adhesion (CD54) molecules on blast cells of acute myelogenous leukemias by TNF- $\alpha$ and IFN- $\gamma$. Cytokines $\mathrm{Mol}$ Ther. 1996;2(3):147-159.

61. Ferm M, Grönberg A, Tally M. IFN- $\gamma$ treatment increases insulin binding and MHC class I expression in erythroleukemia cells. Immunol Invest. 1996;25(1-2):37-47.

62. Lecchi M, Lovisone E, Genetta C, Peruccio D, Resegotti L, Richiardi P. Gamma-IFN induces a differential expression of HLA-DR, DQ and DP antigens on peripheral blood myeloid leukemic blasts at various stages of differentiation. Leuk Res. 1989;13(3):221-226.

63. Dalton DK, Pitts-Meek S, Keshav S, Figari IS, Bradley A, Stewart TA. Multiple defects of immune cell function in mice with disrupted interferon- $\gamma$ genes. Science. 1993;259(5102):1739-1742.

64. Badovinac VP, Harty JT. Adaptive immunity and enhanced $\mathrm{CD}^{+} \mathrm{T}$ cell response to Listeria monocytogenes in the absence of perforin and IFN- $\gamma$. J Immunol. 2000;164(12):6444-6452.

65. White DW, Harty JT. Perforin-deficient CD8 ${ }^{+}$ T cells provide immunity to Listeria monocytogenes by a mechanism that is independent of CD95 and IFN- $\gamma$ but requires TNF- $\alpha$. J Immunol. 1998;160(2):898-905.

66. Garvey TL, et al. Inflammatory responses to pneumovirus infection in IFN- $\alpha \beta$ R gene-deleted mice. JImmunol. 2005;175(7):4735-4744.

67. Smyth GK. 23 limma: linear models for microarray data. In: Gentleman RC, Carey V, Dudoit S, Irizarry R, Huber W, eds. Bioinformatics And Computational Biology Solutions Using R And Bioconductor. New York, New York, USA: Springer; 2005:397-420.

68. Wu D, Smyth GK. Camera: a competitive gene set test accounting for inter-gene correlation. Nucleic Acids Res. 2012;40(17):e133.

69. Subramanian A, et al. Gene set enrichment analysis: a knowledge-based approach for interpreting genome-wide expression profiles. Proc Natl Acad Sci U S A. 2005;102(43):15545-15550. 